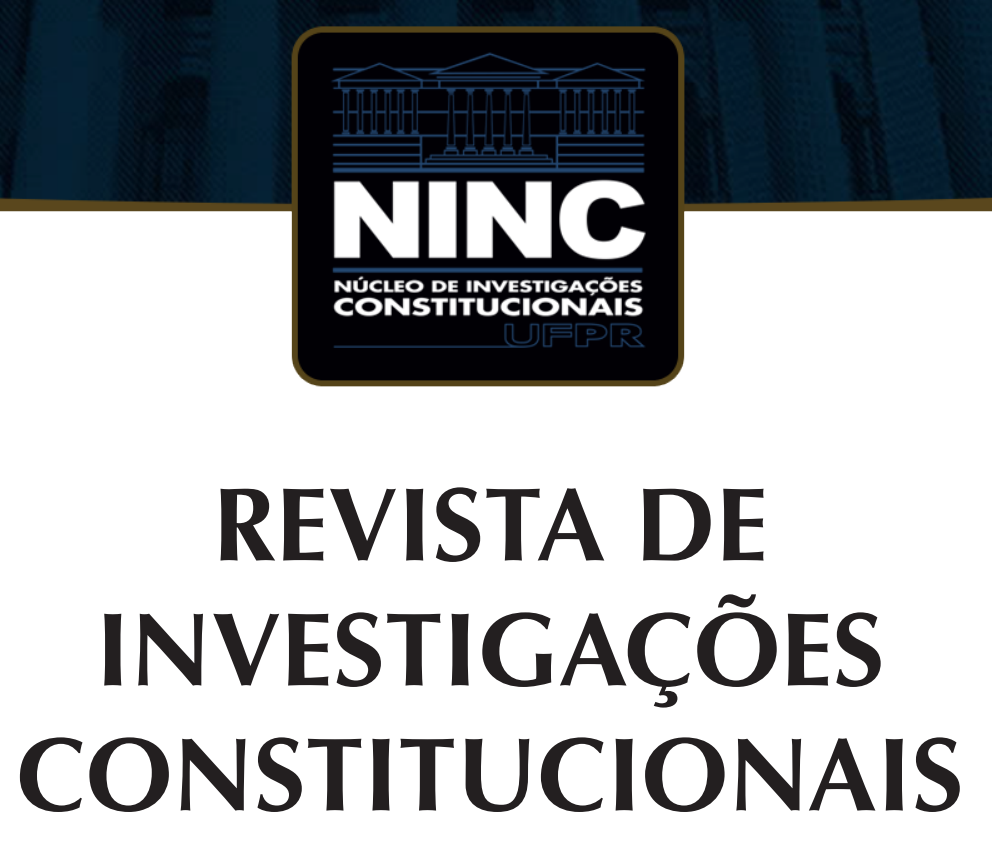

JOURNAL OF CONSTITUTIONAL RESEARCH

vol. 8 | n. 3 | setembro/dezembro 2021 | ISSN 2359-5639 | Periodicidade quadrimestral Curitiba | Núcleo de Investigações Constitucionais da UFPR | www.ninc.com.br 


\title{
Compromisso Significativo: contribuições sul-africanas para os processos estruturais no Brasil
}

\section{Meaningful Engagement: south african contributions to structural litigation in Brazil}

\author{
MATHEUS CASIMIRO GOMES SERAFIM ${ }^{1, *}$ \\ ' Universidade do Estado do Rio de Janeiro (Rio de Janeiro, Rio de Janeiro, Brasil) \\ mcgserafim@gmail.com \\ http://orcid.org/0000-0002-3963-3783 \\ GEORGE MARMELSTEIN LIMA $11, * *$ \\ "Centro Universitário 7 de Setembro (Fortaleza, Ceará, Brasil) \\ georgemlima@yahoo.com.br \\ http://orcid.org/0000-0002-1277-3217 \\ Recebido/Received: 26.06 .2020 / June $26^{\text {th }}, 2020$ \\ Aprovado/Approved: 19.08.2021 / August 19 ${ }^{\text {th }}, 2021$
}

\section{Resumo}

Com a constitucionalização dos direitos econômicos, sociais e culturais (DESCs), o Poder Judiciário passou a ser demandado a enfrentar casos envolvendo a implementação de complexas prestações materiais. Para lidar com esse tipo de demanda, foram desenvolvidos vários modelos de processos estruturais, que podem aumentar o protagonismo judicial. Por conta disso, os litígios es truturais costumam ser criticados com pelo menos três objeções: a incapacidade técnica do Judiciário, a ameaça à separação de poderes e a possibilidade de um efeito backlash, prejudicando o avanço da solução na arena

\section{Abstract}

With the constitutionalization of economic, social and cultural rights, the Judiciary Power has been demanded to face cases involving the implementation of complex material benefits. To deal with this type of demand, several models of structural litigation have been developed, which can increase the judicial role. Because of this, structural litigation are usually criticized with at least three objections: the technical incapacity of the Judiciary, the threat to the separation of powers and the possibility of a backlash effect, hampering the progress of the solution in the political arena. In this context, this article analyzes a structural remedy developed

Como citar esse artigo/How to cite this article: SERAFIM, Matheus Casimiro Gomes; LIMA, George Marmelstein. Compromisso Significativo: contribuições sul-africanas para os processos estruturais no Brasil. Revista de Investigações Constitucionais, Curitiba, vol. 8, n. 3, p. 771-806, set./dez. 2021. DOI: 10.5380/rinc.v8i3.74743.

" Doutorando em Direito Público pela Universidade do Estado do Rio de Janeiro (Rio de Janeiro-RJ, Brasil). Mestre e Graduado em Direito pela Universidade Federal do Ceará (UFC). Especialista em Filosofia e Teoria do Direito pela Pontifícia Universidade Católica de Minas Gerais (PUC-MG). E-mail: mcgserafim@gmail.com.

"* Professor da Graduação e do Mestrado em Direito do Centro Universitário 7 de Setembro (Fortaleza-CE, Brasil). Doutor em Direito, Justiça e Cidadania no Século XXI pela Universidade de Coimbra. Mestre em Direito Constitucional pela Universidade Federal do Ceará (UFC). Juiz federal na Justiça Federal do Ceará. E-mail: georgemlima@yahoo.com.br. 
política. Nesse contexto, o presente artigo analisa um modelo de remédio estrutural desenvolvido pela Corte Constitucional da África do Sul, denominado Compromisso Significativo, que pode minimizar o impacto das referidas objeções, na medida em que amplia a participação comunitária e o diálogo interinstitucional entre os diversos atores responsáveis pela solução do problema. Para além da tradicional pesquisa bibliográfica em torno da doutrina desenvolvida sobre o tema, procedeu-se a uma análise mais aprofundada dos dois casos paradigmáticos que serviram de base para o desenvolvimento do instituto sul-africano: Olivia Road e Joe Slovo. Com base no estudo realizado, conclui-se que existem razões intrínsecas e extrínsecas para buscar inspiração no modelo do Compromisso Significativo.

Palavras-chave: compromisso significativo; processo estrutural; remédio estrutural; áfrica do sul; direito comparado. by the Constitutional Court of South Africa, called Meaningful Engagement, which can minimize the impact of these objections, as it expands community participation and interinstitutional dialogue between the different actors responsible for solving the problem. In addition to the traditional bibliographic research around the doctrine developed on the subject, was carried out a more in-depth analysis of the two paradigmatic cases that served as the basis for the development of the South African institute: Olivia Road and Joe Slovo. Based on the study, it is concluded that there are intrinsic and extrinsic reasons to seek inspiration in the Meaningful Engagement model.

Keywords: meaningful engagement; structural litigation; structural remedy; south africa; comparative law.

\section{SUMÁRIO}

1. Introdução; 2. A resposta do Judiciário às omissões políticas: as sentenças estruturais e a sua utilização no Brasil; 2.1. Os processos estruturais como chaves de acesso para as políticas públicas; 2.2. Os processos estruturais no Brasil; 3. Quando o Judiciário ultrapassa os seus limites: ineficiência, separação de poderes e efeito backlash. 4. A solução sul-africana para os processos estruturais: o Compromisso Significativo; 4.1. O caso Olivia Road v. City of Johannesburg e a origem do Compromisso Significativo; 4.2. O caso Joe Slovo e o aprimoramento do remédio estrutural; 4.3. A importância da participação pública nos processos estruturais e as contribuições do Compromisso Significativo; $\mathbf{5}$. Conclusão; 6. Referências.

\section{INTRODUÇÃO}

Apesar de haver, no Brasil, um amplo debate sobre o controle judicial de políticas públicas desde os anos 1990, o tema ganhou uma nova dimensão, tanto no campo das pesquisas teóricas, quanto das implementações práticas, a partir de 2015. A razão para isso foi o julgamento da medida cautelar da Arguição de Descumprimento a Preceito Fundamental (ADPF) no 347/DF, onde o debate sobre processos estruturais foi explicitamente mencionado pelo Supremo Tribunal Federal (STF).

Naquela ocasião, o STF citou um modelo específico de sentença estrutural, desenvolvido pela Corte Constitucional Colombiana (CCC), denominado de Estado de Coisas Inconstitucional (ECI). Embora o Tribunal não tenha seguido a fórmula procedimental do modelo colombiano, que é marcado pela superação do problema estrutural a partir da realização de sucessivas audiências públicas e um constante monitoramento e medição dos avanços e retrocessos, foram adotadas algumas premissas básicas que 
costumam marcar as demandas estruturais. Por exemplo, foi reconhecido que a solução para os problemas estruturais implica a participação de vários entes de diversas esferas e níveis de poder e que o papel do Judiciário é funcionar como uma espécie de órgão de desobstrução, articulação e coordenação dos trabalhos, a fim de que a solução estrutural seja construída gradualmente, dentro dos limites e das capacidades dos órgãos públicos responsáveis.

Ressalte-se que o problema estrutural da ADPF n³47/DF dizia respeito à crise do sistema penitenciário, marcado pela violação massiva de diversos direitos dos presos que superlotam os presídios brasileiros. Em particular, o que estava em jogo era a privação de direitos básicos relacionados à integridade física e moral das pessoas encarceradas, inclusive os chamados direitos econômicos, sociais e culturais (DESCs).

As demandas estruturais costumam estar sempre associadas à violação dos DESCs, porque tais direitos envolvem complexos mecanismos de prestações sociais que impactam no orçamento e na estrutura dos serviços públicos, gerando dificuldades de implementação. É muito frequente ocorrer problemas de efetividade desses direitos, mesmo em países que os consagram no nível constitucional, pois o mero fato de reconhecer, declarar e positivar formalmente um direito prestacional não implica a sua imediata concretização.

Quando um direito social deixa de ser implementado por inércia de algum órgão público, as pessoas ou grupos prejudicados tendem a recorrer ao Judiciário, buscando proteger seus direitos, seja de modo individual, seja de modo coletivo, ocasião em que as demandas estruturais podem surgir como estratégia para enfrentar a raiz do problema.

Através dos litígios estruturais, busca-se superar uma massiva privação direitos, geralmente de uma significativa quantidade de pessoas, por meio de um processo que conte com a participação de vários órgãos com competência para atuar naquele setor. Por isso, os processos estruturais são complexos, possibilitando que Poder Judiciário exerça um grande protagonismo.

Justamente por colocar os juízes em uma função de destaque, os processos de natureza estrutural costumam ser alvo de várias objeções. De um modo geral, podem-se indicar três críticas mais relevantes: a incapacidade técnica do Judiciário para intervir no âmbito das políticas públicas, conduzindo à ineficiência dos processos estruturais; a ameaça ao princípio da separação de poderes; e a possibilidade de um efeito backlash, tendo em vista uma intervenção judicial indesejada e a reação política e social daí decorrente.

Por causa dessas críticas, o Judiciário, aparentemente, enfrenta um dilema insuperável. Por um lado, pode intervir diretamente na formulação de políticas públicas, ainda que não tenha a capacidade técnica necessária para reorganizar as prioridades do orçamento público e que contrarie a vontade política majoritária, colocando em 
risco a separação de poderes. Por outro, adotando uma postura deferente, pode esvaziar todo o conteúdo normativo dos direitos socioeconômicos, deixando-os dependentes da discricionariedade do Poder Público, colocando em risco a supremacia da Constituição e a inafastabilidade da tutela jurisdicional.

No meio desses dois extremos, que vai da total intervenção à total deferência, há várias possibilidades intermediárias de atuação judicial, que é justamente o que se pretende defender no presente trabalho. O objetivo será apresentar o Compromisso Significativo, modelo de sentença estrutural desenvolvido pela Corte Constitucional da África do Sul, que pode servir de base para o aprimoramento do modelo brasileiro. Por ser um remédio estrutural mais dialogal e participativo, em que não há uma hipertrofia do Judiciário sobre os demais poderes, o Compromisso Significativo pode contribuir com o fortalecimento da democracia participativa.

Como metodologia de pesquisa, realiza-se, além da análise bibliográfica e documental, o estudo de dois casos paradigmáticos para o desenvolvimento do Compromisso Significativo na África do Sul: os casos Olivia Road e Joe Slovo. Esses dois processos foram selecionados para mostrar, com exemplos concretos, como uma Corte Constitucional conseguiu contornar as objeções usualmente apresentadas aos processos estruturais, e quais contribuições essa sentença estrutural pode ofertar para o Brasil, realizadas as devidas adaptações.

\section{A RESPOSTA DO JUDICIÁRIO ÀS OMISSÕES POLÍTICAS: AS SEN- TENÇAS ESTRUTURAIS E A SUA UTILIZAÇÃO NO BRASIL}

O surgimento dos processos estruturais está relacionado ao avanço dos direitos econômicos, sociais e culturais no constitucionalismo contemporâneo, sobretudo ao longo do século XX. De fato, após a Primeira Guerra Mundial, vários países aprovaram constituições contemplando uma ampla diversidade de direitos fundamentais, tratando, inclusive, de matérias que, até então, não eram consideradas como tipicamente constitucionais ${ }^{1}$. Dentre as inovações apresentadas pelas declarações de direitos, é possível destacar a presença dos direitos econômicos, sociais e culturais, tendência iniciada pela Constituição mexicana, de 1917, e pela Constituição de Weimar, de $1919^{2}$.

Outro fenômeno relevante no constitucionalismo contemporâneo ocorreu a partir da Segunda Guerra Mundial, com o desenvolvimento da ideia de dimensão objetiva dos direitos fundamentais, que realça a força irradiante dos valores relacionados à

BEATTY, David M. A essência do Estado de direito. Tradução: Ana Aguiar Cotrim. São Paulo: WMF Martins Fontes, 2014. p. 16.

2 CARVALHO, Osvaldo Ferreira de. As políticas públicas como concretização dos direitos sociais. Revista de Investigações Constitucionais, Curitiba, vol. 6, n. 3, p. 773-794, p. 776 set./dez. 2019. 
dignidade humana e à limitação do poder, exigindo uma atuação constante e proativa do estado em prol da efetivação desses direitos ${ }^{3}$.

A previsão de um extenso rol de direitos, entretanto, não foi suficiente para assegurar a sua concretização. Na verdade, essa positivação teve caráter predominantemente simbólico, e não instrumental, para usar um conceito desenvolvido por Marcelo Neves. O autor explica que toda Constituição possui uma dimensão simbólica, destinada a influenciar o imaginário social, consagrando valores relevantes para a sociedade, e também uma dimensão instrumental, a qual intenta conformar, efetivamente, a realidade política e social subjacente 4 . Quando o caráter simbólico predomina sobre o caráter instrumental, a força normativa da constituição é enfraquecida, gerando um déficit de efetividade, sobretudo em relação aos direitos fundamentais.

Uma das causas da inefetividade dos direitos fundamentais está relacionada às chamadas omissões políticas inconstitucionais, que estão no centro dos processos estruturais ${ }^{5}$. Nesse caso, o termo omissão não se refere a um simples vácuo normativo, até porque é possível que exista ampla diversidade normativa tratando sobre determinado tema e, ainda assim, existir uma grave omissão política. A omissão inconstitucional, nesse contexto, pode ser compreendida como a falta de políticas públicas necessárias à proteção de direitos constitucionalmente assegurados, ocasionando-lhes profundas e reiteradas violações por parte do Poder Público'.

Há várias formas de enfrentar, juridicamente, as omissões inconstitucionais, dentre elas os chamados processos ou demandas estruturais. Os litígios estruturais surgem quando grupos sociais afetados pela inércia estatal buscam a intervenção judicial para alcançar políticas públicas necessárias à proteção dos seus direitos, visando a solução do problema de fundo e não apenas a correção individual da situação.

No próximo tópico, será aprofundado o conceito de processo estrutural, além de serem apresentados alguns modelos mais conhecidos de demandas estruturais.

\footnotetext{
3 MAAS, Rosana Helena; LEAL, Mônia Clarissa Hennig. Controle judicial de políticas públicas: "controle judicial forte ou fraco"?. Revista Direitos Fundamentais \& Democracia, v. 24, n. 1, p. 191-215, p. 201-202, 2019.

4 NEVES, Marcelo. Constitucionalização Simbólica e Desconstitucionalização Fática: Mudança Simbólica de Constituição e Permanência das Estruturas Reais de Poder. Revista de Informação Legislativa, Brasília, v. 33 , n.132, p. 321-330, p. 325, 1996.

5 FERRAZ, Octavio Luiz Motta. Between activism and deference: social rights adjudication in the Brazilian Supreme Federal Tribunal. In: GARCÍA, Helena Alviar; KLARE, Karl; WILLIAMS, Lucy A. (Ed.). Social and Economic Rights in Theory and Practice: Critical Inquiries. Nova York: Routledge Research In Human Rights Law, 2014. p. 121-137, p. 121.

6 MARMELSTEIN, George. A eficácia incompleta das normas constitucionais: desfazendo um mal-entendido sobre o parâmetro normativo das omissões inconstitucionais. Revista Jurídica da Fa7, Fortaleza, v. 12, n. 1, p. 10-28, p. 25, 2015a
} 


\subsection{Os processos estruturais como chaves de acesso para as políticas públicas}

Como se viu, uma omissão inconstitucional acarreta a não-prestação de serviços públicos necessários à concretização de determinados direitos fundamentais. Pelo princípio do acesso à Justiça ou da inafastabilidade da jurisdição, as pessoas prejudicadas, seja de forma direta, seja por meio de órgãos com representatividade adequada, podem buscar uma resposta jurídica capaz de solucionar o problema. Uma vez demandado, o Judiciário terá a prerrogativa de impor o respeito à Constituição, exigindo dos órgãos públicos responsáveis que saiam da inércia, a fim de implementar a prestação do serviço ou do bem em favor daquelas pessoas que tiveram seus direitos violados.

Quando a atuação judicial vai além da correção individual do problema para buscar uma solução massificada, que procure superar de vez a omissão, tem-se o que os processualistas denominam de demanda estrutural, um processo complexo que envolve múltiplos órgãos, interesses e instituições, geralmente públicas.

Os processos estruturais têm, como ponto de partida, a sistemática violação aos direitos fundamentais, mas o objetivo não é apenas reparar os danos já ocasionados, e sim promover uma readequação das políticas públicas necessárias à efetivação dos direitos violados ou reorganizar, estruturalmente, as instituições responsáveis por realizá-las ${ }^{7}$.

Sintetizando o conceito de litígios estruturais, Vitorelli ${ }^{8}$ explica:

Em resumo, litígios estruturais, para os efeitos do presente estudo, são aqueles que envolvem conflitos multipolares, de elevada complexidade, cujo objetivo é promover valores públicos pela via jurisdicional, mediante transformação de uma instituição pública ou privada. Há necessidade de reorganização de toda uma instituição, com a alteração de seus processos internos, de sua estrutura burocrática e da mentalidade de seus agentes, para que ela passe a cumprir sua função de acordo com o valor afirmado pela decisão.

Em vários lugares do mundo, o Judiciário tem desenvolvido modelos de processos estruturais que viabilizem a intervenção judicial no âmbito de atuação dos poderes políticos, no intuito de sanar, ainda que parcialmente, as omissões políticas do Estado. Esses modelos não intentam apenas apontar quem detém a razão no caso concreto,

\footnotetext{
7 VITORELLI, Edilson. 0 devido processo legal coletivo: representação, participação e efetividade da tutela jurisdicional. 2015. 719 f. Tese (Doutorado) - Curso de Direito, Ciências Jurídicas, Universidade Federal do Paraná, Curitiba, 2015. p. 564.

8 VITORELLI, Edilson. Litígios Estruturais: decisão e implementação de mudanças socialmente relevantes pela via processual. In: ARENHART, Sérgio Cruz; JOBIM, Marco Félix (Org.). Processos Estruturais. Salvador: Juspodivm, 2017. p. 369-422, p. 372.
} 
afirmando os direitos que devem ser protegidos ${ }^{9}$. Quando o Judiciário os utiliza, pretender ir além: objetiva intervir no funcionamento das instituições envolvidas nos litígios, para que novas políticas públicas sejam desenvolvidas ou que essas instituições sejam reorganizadas internamente, para sanar as omissões existentes.

Assim, quando a instância judicial recorre ao processo estrutural, o comum é que o próprio arranjo burocrático, responsável por formular e executar políticas públicas, encontre-se com graves problemas, razão pela qual o Judiciário intervém para promover uma reorganização que leve essa estrutura fragilizada para dentro dos limites constitucionais ${ }^{10}$.

As decisões proferidas no âmbito de processos estruturais se orientam para uma perspectiva futura, e não apenas em curto prazo, a fim de evitar que o provimento jurisdicional se converta em um problema maior do que o original ${ }^{11}$. Como explicam Fachin e Bueno", "provimentos desta complexidade tem, por consequência, efeitos também complexos e que assim devem ser apreendidos".

Uma demanda estrutural costuma se alicerçar em um desses três paradigmas principais: o strong-form review, o weak-form review e o democratic experimentalism.

No strong-form review, a chance de uma intervenção jurisdicional ineficiente e violadora da separação de poderes é consideravelmente maior. Isso porque, nesse modelo, o Judiciário dá a última palavra sobre a solução das omissões estatais ${ }^{13}$, influenciando diretamente na formulação de políticas públicas. O órgão judicial responsável pela questão atua de forma solipsista, determinando, em grande parte, como o Poder Público deve agir. Exemplo desse modelo são as structural injunctions, utilizadas pelo Poder Judiciário norte-americano para determinar profundas mudanças em instituições públicas e privadas ${ }^{14}$. Esse é um modelo bastante criticado, inclusive nos Estados Unidos, por acarretar uma hipertrofia da atuação judicial, colocando em risco a própria separação dos poderes.

\footnotetext{
9 OSNA, Gustavo. Nem "tudo", nem "nada" - decisões estruturais e efeitos jurisdicionais complexos. In: ARENHART, Sérgio Cruz; JOBIM, Marco Félix. Processo Estruturais. Salvador: Juspodivm, 2017. p. 177202 , p. 182.

10 FISS, Owen. To make the Constitution a living truth: four lectures on the Structural Injunction. In: ARENHART, Sérgio Cruz; JOBIM, Marco Félix (Org.). Processos Estruturais. Salvador: Juspodivm, 2017. p. 583-607, p. 590.

11 SALAZAR, Rodrigo; MEIRELES, Edilton. Decisões estruturais e acesso à justiça. Revista Cidadania e Acesso à Justiça, [s.I.], v. 3, n. 2, p. 21-38, p. 32, 2 dez. 2017.

12 BUENO, C. C.; FACHIN, Melina Girardi. Decisões estruturantes na jurisdição constitucional brasileira: critérios processuais da tutela jurisdicional de direitos prestacionais. Revista de Estudos Institucionais, v. 4, p. 211246, p. 225, 2018.

13 TUSHNET, Mark V. Weak Courts, Strong Rights: Judicial Review and social welfare rights in comparative constitucional law. Princeton: Princeton University Press, 2008. p. 21.

14 JOBIM, Marco Félix. Medidas Estruturantes: da Suprema Corte Estadunidense ao Supremo Tribunal Federal. Porto Alegre: Livraria do Advogado Editora, 2013. p. 91-93.
} 
Em contrapartida, no weak-form review, busca-se a construção de um diálogo institucional entre os setores políticos e o Judiciário, com o intuito de retirar deste Poder o monopólio sobre a interpretação dos dispositivos constitucionais envolvidos no litígio ${ }^{15}$. Consequentemente, as instâncias judiciais respeitam as funções típicas da Administração Pública e não intentam formular, unilateralmente, as medidas que devem ser adotadas para a superação das omissões políticas. O modelo colombiano, desenvolvido a partir do Estado de Coisas Inconstitucional, poderia ser enquadrado nesse paradigma.

Por fim, tem-se o experimentalismo, defendido por Sabel e Simon ${ }^{16}$ como um desdobramento do weak-form review. No paradigma experimentalista, as Cortes abandonam o seu papel tradicional de apenas julgar, procurando estimular processos deliberativos que envolvam os apartes e outros grupos interessados no litígio, para desenvolverem e implementarem os seus direitos ${ }^{17}$. Portanto, a sua característica distintiva é a grande abertura à participação, tanto do segmento populacional afetado pela omissão política, como das instituições, públicas e privadas, interessadas no litígio estrutural. O Compromisso Significativo, remédio estrutural desenvolvido pela Corte Constitucional da África do Sul, é uma expressão do experimentalismo ${ }^{18}$.

Ciente dos três principais paradigmas que orientam a utilização das sentenças estruturais, resta analisar como os processos estruturais têm se desenvolvido no Brasil.

\subsection{Os processos estruturais no Brasil}

É crescente o número de estudos publicados no país sobre processos estruturais, sobretudo nos últimos dez anos. Os fundamentos desses litígios, no entanto, não são novidade na jurisprudência nacional. O próprio STF já tratou, em diversas circunstâncias, sobre a possibilidade de intervenção do Judiciário no âmbito de atuação dos poderes políticos, sobretudo em questões de saúde, educação e sistema carcerário.

Um caso seminal julgado pelo STF em 2004 foi a ADPF n 45 . Apesar de ter sido uma decisão monocrática, proferida pelo ministro Celso de Mello, a ADPF no 45 contribuiu para fixar a base jurídica para o desenvolvimento dos processos estruturais, especialmente porque sinalizou pela possibilidade da atuação judicial na imposição

15 DIXON, Rosalind. O argumento central a favor da forma fraca de controle de constitucionalidade. Revista Direitos Fundamentais \& Democracia, v. 24, n. 2, p. 5-55, p. 18-19, 2019

16 SABEL, Charles F.; SIMON, William H. Destabilization rights: how public law litigation succeeds. Cambridge: Harvard Law Review, 2004. p. 1019.

17 LIEBENBERG, Sandra; YOUNG, Katharine G. Adjudicating social and economic rights: Can democratic experimentalismo help?. In: GARCÍA, Helena Alviar; KLARE, Karl; WILLIAMS, Lucy A. (Ed.). Social and Economic Rights in Theory and Practice: Critical Inquiries. Nova York: Routledge Research In Human Rights Law, 2014. p. 237-257, p. 237.

18 RAY, Brian. Engaging with Social Rights: Procedure, Participation, and Democracy in South Africa's Second Wave. Cambridge: Cambridge University Press, 2016. p. 24 
de medidas para concretizar direitos fundamentais, ainda que em caráter subsidiário e excepcional. Além disso, foi reconhecido que o Executivo e o Legislativo não possuem irrestrita liberdade de atuação, cabendo ao Judiciário resguardar o mínimo existencial ameaçado pelas omissões estatais ${ }^{19}$.

Seguindo na mesma linha, o Supremo Tribunal Federal, ao julgar o RE n592.581, consignou que o Judiciário pode determinar que a Administração Pública realize reformas emergenciais em presídios para assegurar o mínimo existencial dos detentos. É nesse sentido o teor do tema $n^{\circ} 220$, de repercussão geral e oriundo do julgamento do referido Recurso Extraordinário. Por meio desse enunciado, o STF deixa claro que há "competência do Poder Judiciário para determinar ao Poder Executivo a realização de obrar em estabelecimentos prisionais com o objetivo de assegurar a observância de direitos fundamentais dos presos" 20 .

Ainda que tais casos tenham propiciado uma maior intervenção judicial na elaboração e execução de políticas públicas, o principal marco para os processos estruturais foi o reconhecimento, pela primeira vez no Brasil, de que o sistema prisional brasileiro poderia ser diagnosticado como um "Estado de Coisas Inconstitucional", no julgamento da medida cautelar da ADPF n 347/DF, em 2015, mencionada na introdução deste artigo.

A decisão proferida na ADPF n 347/DF teve um grande impacto no direito brasileiro. Primeiro, porque estabeleceu ao Conselho Nacional de Justiça o dever de regular, em âmbito nacional, a chamada audiência de custódia, além de ter determinado várias medidas para minimizar a crise do sistema carcerário brasileiro. Segundo, porque inspirou a comunidade acadêmica a pesquisar sobre demandas estruturais e a desenvolver modelos processuais adequados à realidade brasileira ${ }^{21}$.

Ressalte-se que a referida ação foi proposta pelo Partido Socialismo e Liberdade (PSOL), com o suporte jurídico da Clínica de Direitos Humanos da Universidade Estadual do Rio de Janeiro. Nos pedidos da ação, o PSOL requereu, dentre outros pleitos, que o STF reconheça o Estado de Coisas Inconstitucional do sistema prisional; que o Governo Federal elabore e encaminhe ao STF, no prazo máximo de 3 meses, um Plano Nacional visando a superação do $\mathrm{ECI}$ do sistema penitenciário brasileiro, dentro de um

19 BRASIL. Supremo Tribunal Federal. Arguição de Descumprimento de Preceito Fundamental n 45/DF. Relator: Ministro Celso de Mello. Diário Oficial da União. Brasília, 2004. Disponível em: http://www.sbdp.org.br/ arquivos/material/343_204\%20ADPF\%202045.pdf. Acesso em: 17 abr. 2020.

20 BRASIL. Supremo Tribunal Federal. Recurso Extraordinário n 592.581. Relator: Ministro Ricardo Lewandowski. Diário Oficial da União. Brasília, 2015a. Disponível em: http://www.stf.jus.br/portal/jurisprudenciaRepercussao/verAndamentoProcesso.asp?incidente $=2637302$ \& numeroProcesso $=592581$ \&classeProcesso=RE\&numeroTema=220. Acesso em: 17 abr. 2020.

21 PEREIRA, Jane Reis Gonçalves; GONÇALVES, Gabriel Accioly. Inconstitucionalidade sistêmica e multidimensional: transformações no diagnóstico das violações à Constituição. JURISPOIESIS, v. 18, p. 130-159, p. 146, 2015. 
prazo de 3 anos; que o STF delibere sobre o Plano Nacional, para homologá-lo ou impor medidas alternativas ou complementares, que reputar necessárias para a superação do crise $^{22}$.

Na decisão, o ministro Marco Aurélio, seguido por outros ministros, mencionou explicitamente o conceito de demanda estrutural, baseando-se, pelo menos retoricamente, no modelo colombiano. A decisão, contudo, seguiu uma linha mais injuncional, determinando obrigações a vários órgãos públicos, inclusive para que fosse resolvido o problema de contingenciamento de verbas do Fundo Penitenciário Nacional, ponto crucial para garantir recursos financeiros capazes de superar o problema ${ }^{23}$.

Uma das críticas à atuação do STF, na ADPF n 347/DF, é no sentido de se criar um modelo de processo estrutural que aumente demasiadamente os poderes judiciais. De fato, há um risco de se transformar o Judiciário em uma instância revisora dos trabalhos do Executivo, com o poder de alterar ou complementar os planos que serão formulados com quaisquer medidas que, em seu entender, sejam necessárias, podendo ignorar até as análises técnicas desenvolvidas pelos órgãos administrativos competentes. Por essa razão, Vieira e Bezerra ${ }^{24}$, analisando a adoção do ECI na ADPF no 347/DF, afirmam que a forma como o instituto foi adotado no País, sem considerar a premente necessidade de promover um redesenho institucional, acaba por esvaziá-lo. É esse também o pensamento de Magalhães ${ }^{25}$, que afirma:

Do ponto de vista dogmático, não é tarefa simples explicar a inserção do $\mathrm{ECl}$ no direito constitucional brasileiro. A decisão do STF na ADPF 347 é inconsistente na caracterização dos pressupostos que justificariam a declaração de um $\mathrm{ECl}$, as medidas cautelares deferidas são pouco efetivas, há uma injustificada demora no julgamento do mérito, os poderes apresentaram respostas pouco substantivas e que seguem a mesma natureza das políticas tradicionalmente desenvolvidas no Brasil e a capacidade de uma Corte Suprema mudar um estado fático de coisas por meio do Direito é posta em dúvida.

22 BRASIL. Supremo Tribunal Federal. Arguição de Descumprimento de Preceito Fundamental No 347/DF. Relator: Ministro Celso de Mello. Diário Oficial da União. Brasília, 2015b. p. 70-73. Disponível em: http://www. jota.info/wp-content/uploads/2015/05/ADPF-347.pdf. Acesso em: 25 abr. 2020.

23 VIEIRA JUNIOR, R. J. A. Separação de Poderes, Estado de Coisas Inconstitucional e Compromisso Significativo: novas balizas à atuação do Supremo Tribunal Federal. Brasília: Núcleo de Estudos e Pesquisas/ CONLEG/Senado, Dezembro/2015 (Texto para Discussão no 186). p. 19. Disponível em: https://www12.senado.leg.br/publicacoes/estudoslegislativos/tipos-de-estudos/textos-para-discussao/td186. Acesso em: 09 mai. 2020.

24 VIEIRA, J. R.; BEZERRA, R. Estado de coisas fora do lugar: uma análise comparada entre a Sentencia T025 e a ADPF 347/DF-MC. In: VIEIRA, José Ribas; CAMARGO, Margarida Maria Lacombe; SIDDHARTA, Legale. (Org.). Jurisdição constitucional e direito constitucional internacional. Belo Horizonte: Editora Fórum, 2016. p. 203-223, p. 221.

25 MAGALHÃES, Breno Baía. O Estado de Coisas Inconstitucional na ADPF 347 e a sedução do Direito: o impacto da medida cautelar e a resposta dos poderes políticos. Revista Direito GV, [s.l.], v. 15, n. 2, p. 1-37, p. 31-32, 2019 
As críticas são, em grande medida, procedentes, sobretudo porque o STF não seguiu as técnicas mais dialogais utilizadas pela Corte Constitucional Colombiana ao desenvolver o Estado de Coisas Inconstitucional. Ao invés de impor medidas concretas e estabelecer obrigações a serem realizadas, a CCC costuma reforçar as responsabilidades de cada órgão, exercendo muito mais uma função de articulação, coordenação e desbloqueio de entraves burocráticos do que jurisdicional.

Atualmente, existem outras tentativas de adaptar o Estado de Coisas Inconstitucional para a realidade brasileira. Por exemplo, na ADPF n 682, proposta em 07/05/2020, o Conselho Federal da OAB pediu a suspensão das autorizações para criação de novos cursos jurídicos que ainda não iniciaram o seu funcionamento, bem como o veto à abertura de novas vagas em instituições privadas. Dentre os pleitos apresentados, a entidade requer ao Tribunal "reconhecer o Estado de Coisas Inconstitucional referente à situação do ensino jurídico, em decorrência da violação sistemática ao preceito constitucional que garante a qualidade do ensino jurídico superior (art. 209, CF)"26. Aqui se nota, mais uma vez, uma deturpação da lógica do instituto, que tem como pressuposto uma violação massiva de grupos vulneráveis, bem como a inércia estrutural de vários entes públicos e privados, e não simplesmente um apelo retórico diante de uma falha genérica de serviços públicos e/ou privados.

De qualquer modo, o que se percebe são vários riscos decorrentes de uma má utilização do $\mathrm{ECl}$, que tem, inclusive, gerado um backlash no meio político contra a atuação judicial sem parâmetros objetivos. Nesse sentido, o senador Antônio Carlos Valadares apresentou, em 11 de novembro de 2015, o Projeto de Lei do Senado (PLS) nº $736 / 2015^{27}$, que, além de estabelecer pressupostos objetivos a serem observados pelo Tribunal para o reconhecimento do $\mathrm{ECl}$, determina também que o reconhecimento desse estado de coisas fosse precedido da celebração de um Compromisso Significativo entre o Poder Público e os segmentos populacionais afetados, o que foi notoriamente inspirado no modelo da África do Sul, que será aqui apresentado.

A mensagem que podemos extrair, a partir dos desdobramentos da ADPF no 347/DF, é que o STF ainda não acolheu, infelizmente, um modelo mais dialógico de processo estrutural. Predomina a visão tradicional de adjudicação, em que o papel do

26 BRASIL. Supremo Tribunal Federal. Arguição de Descumprimento de Preceito Fundamental no 682. Relator: Ministro Ricardo Lewandowski. Diário Oficial da União. Brasília, 2020. p. 70. Disponível em: https://www.jota. info/wp-content/uploads/2020/05/oab-suspensao-cursos-dedireito.pdf. Acesso em: 09 mai. 2020.

27 BRASIL. Projeto de Lei do Senado $\mathbf{n}^{\circ} \mathbf{7 3 6 / 2 0 1 5}$. Altera as Leis $n^{\circ} \mathbf{9 . 8 8 2}$, de 3 de dezembro de 1999, e 13.105, de 16 de março de 2015, para estabelecer termos e limites ao exercício do controle concentrado e difuso de constitucionalidade pelo Supremo Tribunal Federal, dispor sobre o estado de coisas inconstitucional e o compromisso significativo. Brasília, 2015c. Disponível em: https://www25.senado.leg.br/web/atividade/ materias/-/materia/124010. Acesso em: 02 jan. 2020. 
poder judiciário é decidir e impor soluções, mesmo que isso implique a alteração de estruturas organizacionais profundas ${ }^{28}$.

Por conta disso disso, é necessário reforçar a necessidade de buscar alternativas ao modelo estrutural conduzido pelo STF, de tal forma que o Judiciário possa promover a efetivação dos direitos socioeconômicos, sem tomar para si a função de elaborar as políticas públicas exigidas pelo caso concreto.

\section{QUANDO O JUDICIÁRIO ULTRAPASSA OS SEUS LIMITES: INEFI- CIÊNCIA, SEPARAÇÃO DE PODERES E EFEITO BACKLASH}

Conforme visto na introdução, costuma-se criticar o controle jurisdicional de políticas públicas com base em três argumentos centrais: a incapacidade técnica do Judiciário para formular políticas públicas, o que pode levar à ineficiência do processo estrutural; a violação do princípio da separação de poderes; e a ocorrência de um efeito backlash. É importante analisar as três objeções em conjunto, já que o último tópico deste trabalho apresenta as contribuições do Compromisso Significativo para a superação dessas críticas.

A primeira questão levantada contra a intervenção judicial no âmbito das políticas públicas é o clássico argumento de que o Judiciário, ao proceder dessa forma, usurpa competências exclusivas dos poderes políticos. Na concepção mais rígida da separação de poderes, "[...] sempre haverá um núcleo essencial da função que não é passível de ser exercido senão pela Poder competente"29. Foi, com base nessa argumentação, inclusive, que muitos criticaram a introdução de direitos sociais na nova Constituição sul-africana ${ }^{30}$. Olhando a questão por essa perspectiva, para que o Judiciário possa promover a efetividade desses direitos, é inevitável que interfira, em alguma medida, no âmbito de atuação do Executivo, razão pela qual seria melhor não os incluir no texto constitucional.

Em segundo lugar, tem-se a incapacidade técnica dos membros do Judiciário para intervir em políticas públicas. Os órgãos jurisdicionais são compostos por magistrados que têm o Direito como formação acadêmica, não reunindo, em tese, conhecimentos suficientes para realizar realocações orçamentárias ou analisar todos os fatores envolvidos na formulação de uma política pública. O mesmo pode ser dito de seus assessores, que os auxiliam no embasamento jurídico das decisões, mas não são, em

28 SCOTT, Joanne; STURM, Susan. Courts as catalysts: re-thinking the judicial role in new governance. Columbia Journal of European Law, v. 13, p. 565-594, p. 569, 2006.

29 RAMOS, Eival da Silva. Ativismo Judicial: parâmetros dogmáticos. 2. ed. São Paulo: Saraiva, 2015. p. 118.

30 RAY, Brian. Engaging with Social Rights: Procedure, Participation, and Democracy in South Africa's Second Wave. Cambridge: Cambridge University Press, 2016. p. 35. 
regra, especialistas em outras áreas de conhecimento, que são fundamentais para a criação de políticas públicas adequadas.

As demandas estruturais envolvem um extenso rol de complexas questões econômicas, sociais e culturais, não sendo uma tarefa fácil fixar a solução para as omissões políticas que originaram o litígio ${ }^{31}$. Assim, uma atuação unilateral da instância judicial pode não só violar a separação de poderes, mas conduzir à aplicação de medidas paliativas, que, na melhor das hipóteses, produzem efeitos em curto prazo, porém não resolvem o verdadeiro problema.

Por último, tem-se a possibilidade de uma sentença estrutural gerar um efeito backlash que comprometa a sua eficiência. O termo tem sido utilizado para designar uma contundente reação contrária a decisões judiciais consideradas excessivamente progressistas, e que pode advir tanto da sociedade quanto dos poderes políticos instituídos, comprometendo a eficiência da sentença proferida ${ }^{32}$. O fenômeno tende a ocorrer quando uma decisão diverge, consideravelmente, da normatização consagrada socialmente ou das instituições em relação às quais segmentos influentes da população mantenham uma significativa fidelidade normativa ${ }^{33}$.

Exemplo recente do fenômeno, no Brasil, foi o caso da vaquejada, declarada inconstitucional pelo STF, que reconheceu como inválida a Lei n 15.299/2013, a qual regulamentava a atividade no estado do Ceará e teve sua constitucionalidade questionada na ADI n 4.983. Reagindo à decisão proferida em 2016, o Congresso Nacional aprovou a Emenda Constitucional no 96/2017, estabelecendo que as práticas desportivas que utilizem animais não são cruéis, desde que sejam uma manifestação cultural ${ }^{34}$.

Um bom exemplo de como os referidos problemas podem comprometer os efeitos de uma sentença estrutural pode ser observado no histórico do Estado de Coisas Inconstitucional, na própria Colômbia.

Analisando o desenvolvimento do $\mathrm{ECl}, \mathrm{Campos}^{35}$ conclui que é possível diferenciar duas fases principais na aplicação do instituto: a primeira, marcada pela ineficiência

\footnotetext{
31 ARENHART, Sérgio Cruz. Processo multipolar, participação e representação de interesses concorrentes. In: ARENHART, Sérgio Cruz; JOBIM, Marco Félix (Org.). Processos Estruturais. Salvador: Juspodivm, 2017. p. 423448, p. 448.

32 KOZICKI, Katya. Backlash: as "reações contrárias" à decisão do Supremo Tribunal Federal na ADPF no 153. In: SOUZA JÚNIOR, José Geraldo de et al. (Org.). O Direito Achado na Rua: introdução crítica à justiça de transição na América Latina. Brasília: UnB, 2015. v. 7, p. 192-196, p. 194.

33 VALLE, Vanice Regina Lírio do. Backlash à decisão do Supremo Tribunal Federal: pela naturalização do dissenso como possibilidade democrática [online]. 2013. p. 9. Disponível em: https://www.academia. edu/5159210/Backlash_\%C3\%A0_decis\%C3\%A3o_do_Supremo_Tribunal_Federal_pela_naturaliza\%C3\%A7\%C3\%A3o_do_dissenso_como_possibilidade_democr\%C3\%A1tica. Acesso em: 20 jun. 2020.

34 CARVALHO, Márcia Haydée Porto de; MURAD, Rakel Dourado. O caso da vaquejada entre o Supremo Tribunal Federal e o Poder Legislativo: a quem cabe a última palavra?. Revista de Biodireito e Direito dos Animais, [s.l.], v. 3, n. 2, p. 18-37, p. 35, dez. 2017.

35 CAMPOS, Carlos Alexandre de Azevedo. Estado de Coisas Inconstitucional. Salvador: Juspodium, 2016. p. 167.
} 
e por intervenções solipsistas do judiciário, cujo maior exemplo é a sentença T-153; já a segunda, iniciada com a sentença T-25, é caracterizada pelo rigor na identificação de situações que verdadeiramente ensejam o reconhecimento do $\mathrm{ECl}$, bem como por uma maior preocupação com a eficiência das demandas estruturais.

Assim como ocorre hoje no Brasil, a Colômbia possuía um sistema prisional faIho, permeado de graves violações aos direitos fundamentais dos encarcerados e comprometido pelo processo de superlotação ${ }^{36}$. Diante dessa realidade, diversas ações de tutela $^{37}$ foram propostas no intuito de exigir do Estado uma solução. Inicialmente, as ações ajuizadas tratavam do sistema prisional das cidades de Bogotá e Bellavista, entretanto, percebendo que semelhantes violações aos direitos fundamentais eram encontradas em prisões de todo o país, a Corte Constitucional Colombiana reconheceu o ECI de todo o sistema carcerário, na tentativa de superar as omissões políticas existentes.

À vista disso, a Corte determinou uma série de medidas que deveriam ser adotadas pelas instituições prisionais, a fim de proteger os direitos fundamentais dos encarcerados. Essas medidas incluíam reformulações nas políticas públicas existentes, construção de novos módulos prisionais e reorganização das disposições orçamentárias, com o intuito de dar uma prioridade fiscal maior para a crise existente ${ }^{38}$.

Ainda que a atuação jurisdicional tenha sido imbuída de boas intenções, os objetivos pretendidos pela Corte não foram alcançados, isso porque, conforme explicam Garavito e Franco ${ }^{39}$, a CCC adotou uma postura de legitimidade duvidosa e ineficiente, focando em soluções impostas unilateralmente e que produziram efeitos, sobretudo, em curto prazo. Analisando as razões para esse fracasso, Maia ${ }^{40}$ aponta três fatores principais: medidas excessivamente rigorosas e impostas de forma unilateral pela Corte,

36 MARMELSTEIN, George. O Estado de Coisas Inconstitucional: uma análise panorâmica. In: OLIVEIRA, Pedro Augusto de; LEAL, Gabriel Prado (Org.). Diálogo Jurídicos Luso-Brasileiros Volume 1 perspectivas atuais de Direto Público: o Direito em tempos de crise. Salvador: Faculdade Baiana de Direito, 2015b, p. 241- 264.

37 A ação de tutela é um instrumento processual introduzido pela Constituição Colombiana de 1991, no intuito de proteger a dimensão subjetiva dos direitos fundamentais. Valendo-se dessa ação, introduzida pela Constituição Colombiana de 1991, qualquer pessoa pode ingressar em juízo pleiteando proteção aos seus direitos fundamentais, que eventualmente estejam ameaçados pela ação ou omissão de qualquer autoridade pública. VARGAS HERNÁNDEZ, Clara Inés. La garantía de la dimensión objetiva de los derechos fundamentales y labor del juez constitucional colombiano en sede de acción de tutela: El llamado"Estado de cosas inconstitucional" Estudios Constitucionales, v. 1, n. 1, 2003. p. 203- 228, p. 205-206.

38 MAIA, Isabelly Cysne Augusto. Análise da ADPF no 347 e da inadequabilidade do Estado de Coisas Inconstitucional para a efetivação dos serviços públicos: por novos protagonistas na esfera pública democrática. 2018. 177 f. Dissertação (Mestrado) - Curso de Direito, Universidade Federal do Ceará, Fortaleza, 2018. p. 26.

39 GARAVITO, César Rodríguez; FRANCO, Diana Rodríguez. Cortes y cambio social: Cómo la Corte Constitucional transformó el desplazamiento forzado en Colombia. Bogotá: Colección de Justicia, 2010. p. 36.

40 MAIA, Isabelly Cysne Augusto. Análise da ADPF n 347 e da inadequabilidade do Estado de Coisas Inconstitucional para a efetivação dos serviços públicos: por novos protagonistas na esfera pública democrática. 2018. 177 f. Dissertação (Mestrado) - Curso de Direito, Universidade Federal do Ceará, Fortaleza, 2018. p. 36. 
ausência de meios de fiscalização por parte do Judiciário e tangenciamento do cerne da questão carcerária do país.

Ao proferir a sentença T-153, a Corte determinou uma série de alterações nas políticas públicas estatais sem dialogar com os poderes políticos competentes para realizá-las. O resultado desses comandos foi o documento General Program to Comply with Constitutional Court Ruling T-153 of April 28, 1998 pelo INPEC (Instituto Nacional de Penitenciárias e Prisões) ${ }^{41}$, o qual estabeleceu a criação de novos módulos prisionais para dois mil presos, bem como determinou a construção de três complexos carcerários, responsáveis por criar cinco mil e seiscentas novas vagas no sistema prisional.

Além dessa atuação unilateral, Ariza $^{42}$ aponta que a CCC não estabeleceu formas eficientes de fiscalização, da mesma maneira que não explicou como a reforma de presídios existentes seria a melhor solução em longo prazo e, principalmente, não realizou discussões sobre a razão dos altos níveis de encarceramento do país. Consequentemente, a sentença T-153, ainda que em um primeiro momento tenha contribuído com a redução da superlotação prisional, funcionou como uma medida paliativa, apenas adiando o retorno da crise ${ }^{43}$. A prova de que essa decisão foi ineficiente é que a Corte reconheceu o $\mathrm{ECl}$ do sistema penitenciário em outras duas decisões: a decisão T-338, de 2013, e a T-162, de $2015^{44}$.

Em estudo sobre a eficiência da medida cautelar concedida na ADPF n³47/DF e como os poderes políticos reagiram à decisão, Magalhães ${ }^{45}$ defende que os pedidos finais aproximam, negativamente, os dois países, afirmando ainda que a centralização da formalização de planos de ação e de políticas públicas pelo STF enfraquece politicamente o Executivo e o Legislativo, os quais não têm incentivos suficientes para fornecer, autonomamente, os meios para solucionar a crise do sistema prisional.

Apesar da força dos argumentos apresentados pelos opositores dos litígios estruturais, bem como dos exemplos de excessiva intervenção judicial que conduz à

41 ARIZA, Libardo José. The Economic and Social Rights of Prisoners and Constitutional Court Intervention in the Penitentiary System in Colombia. In: MALDONADO, Daniel Bonilla. Constitutionalism of the Global South: The activist tribunals of India, South Africa, and Colombia. New York: Cambridge University Press, 2013. p. 129-162, p. 153.

42 ARIZA, Libardo José. The Economic and Social Rights of Prisoners and Constitutional Court Intervention in the Penitentiary System in Colombia. In: MALDONADO, Daniel Bonilla. Constitutionalism of the Global South: The activist tribunals of India, South Africa, and Colombia. New York: Cambridge University Press, 2013. p. 129-162, p. 153.

43 CHAGAS, Tayná Tavares das et al. Estado de coisas inconstitucional: um estudo sobre os casos colombiano e brasileiro. Revista Quaestio luris, [s.I.], v. 8, n. 4, p. 2.596-2.612, 2015.

44 CAMPOS, Carlos Alexandre de Azevedo. Estado de Coisas Inconstitucional. Salvador: Juspodium, 2016. p. 133.

45 MAGALHÃES, Breno Baía. O Estado de Coisas Inconstitucional na ADPF 347 e a sedução do Direito: o impacto da medida cautelar e a resposta dos poderes políticos. Revista Direito GV, [s.I.], v. 15, n. 2, p. 1-37, p. 31, 2019. 
ineficiência das decisões, o presente estudo intenta demonstrar que os riscos apontados podem ser contornados com base em um modelo mais dialógico de sentença estrutural, como o desenvolvido pela África do Sul.

\section{A SOLUÇÃO SUL-AFRICANA PARA OS PROCESSOS ESTRUTU- RAIS: O COMPROMISSO SIGNIFICATIVO}

Ao analisar a eficiência das intervenções judiciais em prol da efetivação de direitos socioeconômicos, David Landau ${ }^{46}$ aponta a importância de estudar a experiência sul-africana. Em sua opinião, a atuação da Corte Constitucional do país é um exemplo do que não deve ser feito em matéria litígios estruturais. Argumenta que as sentenças estruturais dialógicas não são capazes de obter bons resultados, falhando em proteger os segmentos sociais mais carentes e marginalizados. Para o autor ${ }^{47}$, a solução é uma intervenção mais firme por parte do Judiciário.

O propósito deste tópico é mostrar porque afirmações como as de Landau estão equivocadas, sobretudo ao negar a importância de um diálogo interinstitucional para a busca da superação de problemas estruturais. De início, é preciso concordar com a importância do estudo da experiência constitucional sul-africana, que tem sido riquíssima em várias searas, inclusive nos litígios estruturais. Mas não se pode concordar com a afirmação de Landau de que o modelo sul-africano não merece servir de inspiração. A posição do autor é baseada em um precedente mais antigo, o caso Grootboom ${ }^{48}$, não levando em conta outros importantes julgados posteriores.

Neste artigo, dois casos posteriores a Grootboom são estudados: Olivia Road e Joe Slovo. Esses dois precedentes são fundamentais para a compreensão daquilo que veio a ser conhecido como Compromisso Significativo, instituto que não foi objeto da análise de Landau.

Ao julgar processos estruturais, a Corte Constitucional sul-africana, ainda que tenha variado ao longo do tempo a sua abordagem quanto aos direitos socioeconômicos ${ }^{49}$, possui um perfil claro quanto aos limites de intervenção no âmbito das polí-

46 LANDAU, David. The Reality of Social Rights Enforcement. Harvard International Law Journal, v. 53, n. 1, 2012, p. 190-247, p. 192.

47 LANDAU, David. The Reality of Social Rights Enforcement. Harvard International Law Journal, v. 53, n. 1, 2012, p. 190-247, p. 245-246.

48 Caso emblemático da África do Sul, no qual uma comunidade de 900 pessoas foi expulsa de uma propriedade privada, ficando sem moradia fixa e sendo obrigada a se instalar em alojamentos improvisados. O caso foi levado à Corte Constitucional, a qual determinou que o Poder Público deveria criar e implementar, conforme os recursos disponíveis, um programa destinado a efetivar o direito ao acesso à moradia adequada, capaz de providenciar socorro para aqueles que estariam vivendo em condições deploráveis WESSON, Murray. Grootboom and Reassessing: Beyond the Socioeconomic Jurisprudence of the South African Constitutional Court.

South African Journal On Human Rights, [s.I.], v. 20, n. 2, p. 284-308, jan. 2004.

49 Tentando compreender a atuação da Corte em litígios que envolvem direitos socioeconômicos, Wilson e Dugard (2011, p. 35-36) dividem os casos a ela submetidos em dois grupos, os quais chamam de primeira e 
ticas públicas. Sempre esteve mais confortável promovendo a eficácia desses direitos de forma dialógica, apontando a inconstitucionalidade de atuações do Poder Público sem, todavia, determinar unilateralmente o conteúdo das políticas públicas que devem ser realizadas ${ }^{50}$. É por isso que Roux ${ }^{51}$, analisando a relação entre a Corte e os setores políticos, afirma que o tribunal foi bem-sucedido em intervir em uma das áreas mais sacrossantas do setor político: a formulação de políticas públicas. E foi tentando promover a eficiência dos direitos socioeconômicos, enquanto respeita às competências do Executivo, que a Corte desenvolveu o Compromisso Significativo, que será aqui analisado a partir dos dois casos paradigmáticos já mencionados, começando pelo caso Olivia Road.

\subsection{O caso Olivia Road v. City of Johannesburg e a origem do Compro- misso Significativo}

Ainda que o Compromisso Significativo não seja utilizado apenas para assegurar o direito à moradia, a sua primeira utilização ocorreu em um caso de despejo, promovido pela cidade Johanesburgo.

Entre os anos de 2002 e 2006, tornou-se comum a realização de despejos em massa nas periferias da cidade ${ }^{52}$, no intuito de efetivar programas de revitalização urbana. Durante o período do apartheid, o governo sul-africano conseguiu segregar, no espaço urbano, a população negra ${ }^{53}$. Enquanto a minoria branca, geralmente, vivia mais próxima aos centros das cidades, a maioria da população negra residia em regiões periféricas. Por isso, nesses locais, era comum encontrar milhares de pessoas morando em prédios inadequados para a habitação. Com a instauração do regime democrático, uma

\footnotetext{
segunda onda de litígios sociais. Ao julgar os casos da primeira onda, a Corte enfrentou a tarefa de estabelecer um paradigma interpretativo que possibilitasse a efetivação dos direitos socioeconômicos, enquanto mantivesse a sua estabilidade institucional. Já os casos da segunda onda consolidam o processo de proceduralização: a Corte foca mais em promover a democracia participativa por meio dos litígios que tratem de direitos sociais, incluindo os segmentos populacionais afetados pelas omissões políticas no processo de formulação de políticas públicas. É nessa segunda fase que a Corte desenvolve o Compromisso Significativo, sentença estrutural dialógica que inclui os segmentos populacionais afetados na resolução do litígio. WILSON, Stuart; DUGARD, Jackie. Constitutional Jurisprudence. Socio-economic Rights In South Africa, [s.I.], p. 35-62, p. 3536, 2011. Cambridge University Press.

50 RAY, Brian. Engaging with Social Rights: Procedure, Participation, and Democracy in South Africa's Second Wave. Cambridge: Cambridge University Press, 2016. p. 41-43.

51 ROUX, Theunis. Legitimating Transformation: Political Resource Allocation in the South African Constitutional Court. In: GLOPPEN, Siri; GARGARELLA, Roberto; SKAAR, Elin. Democratization and the judiciary: The Accountability Function of Courts in New Democracies. London: Frank Cass Publishers, 2005. p. 66-80. p. 76-77. 52 WILSON, Stuart. Litigating Housing Rights in Johannesburg's Inner City: 2004 - 2008. South African Journal On Human Rights, [s.I.], v. 27, n. 1, p. 127-151, p. 135, jan. 2011.

53 CLOETE, Clireesh Terry. A critical analysis of the approach of the courts in the application of eviction remedies in the pre-constitutional and constitutional context. 2016. $231 \mathrm{f}$. Dissertação (Mestrado) - Curso de Direito, Stellenbosch University, Stellenbosch, 2016. p. 78.
} 
das principais preocupações do Poder Público, tanto o nacional quanto o municipal, era promover uma reestruturação dessas residências, proporcionando moradia digna para os segmentos sociais marginalizados.

Para o governo de Johanesburgo, o despejo era uma medida necessária, tendo em vista as condições insalubres em que se encontravam as construções residenciais nas periferias da cidade. No plano de regeneração municipal, datado de 2004, é possível verificar algumas das justificativas utilizadas: prédios em más condições, aumento das moradias em condições insalubres e aumento da criminalidade nessas regiões ${ }^{54}$. Ao todo, os despejos atingiram mais de 67.000 pessoas.

Os planos desenvolvidos pela cidade, entretanto, pecavam em um importante ponto: nas suas 53 páginas, não se encontrava qualquer discussão sobre o que aconteceria com os moradores despejados, ou como a seção $26^{55}$ da Constituição seria respei$\operatorname{tada}^{56} \mathrm{Em}$ vez disso, o plano focava, principalmente, em obter investimentos privados para a sua realização e em delinear formas de promover a valorização dos imóveis da região. Além de ignorar a condição da população que perderia a sua moradia, o plano intentava identificar novos meios jurídicos que tornassem os despejos mais rápidos e efetivos ${ }^{57}$, diminuindo a possibilidade de oposição pelos residentes, que careciam de conhecimentos e recursos para contestar legalmente as ações do Poder Público.

O caso Olivia Road tem início quando a cidade de Johanesburgo ajuíza uma ação no Tribunal Regional de Witwatersrand ${ }^{58}$, solicitando a autorização judicial para despejar mais 400 residentes de prédios que seriam reestruturados. OTribunal Regional rejeitou o pedido de despejo do governo municipal, entendendo que a cidade violou a seção 26 da Constituição, a qual assegura o direito à moradia, já que a municipalidade

54 RAY, Brian. Engaging with Social Rights: Procedure, Participation, and Democracy in South Africa's Second Wave. Cambridge: Cambridge University Press, 2016. p. 111.

55 26. Housing.- (1) Everyone has the right to have access to adequate housing. (2) The state must take reasonable legislative and other measures, within its available resources, to achieve the progressive realisation of this right. (3) No one may be evicted from their home, or have their home demolished, without an order of court made after considering all the relevant circumstances. No legislation may permit arbitrary evictions. ÁFRICA DO SUL. Constituição (1996). Constitution Of The Republic Of South Africa No. 108 of 1996. Pretória, 1996. p. 1255. Disponível em: https://www.gov.za/sites/default/files/images/a108-96.pdf. Acesso em: 10 mar. 2020

56 RAY, Brian. Engaging with Social Rights: Procedure, Participation, and Democracy in South Africa's Second Wave. Cambridge: Cambridge University Press, 2016. p. 111.

57 RAY, Brian. Engaging with Social Rights: Procedure, Participation, and Democracy in South Africa's Second Wave. Cambridge: Cambridge University Press, 2016. p. 111.

58 Os Tribunais Superiores (High Courts) ocupam a segunda instância judicial da África do Sul, com jurisdição em uma área delimitada geograficamente. Já o Supremo Tribunal de Apelação (Supreme Court of Appeal) equivale ao Superior Tribunal de Justiça no Brasil. Localizado em Bloemfontein, a SCA é a última instância para discussões acerca de matérias infraconstitucionais, cujas decisões serão vinculantes para todos os tribunais inferiores. SAMPAIO, Karinne F. O controle e a implementação do direito à saúde: a jurisprudência da África do Sul. Revista Digital Constituição e Garantia de Direitos, v. 9, p. 85-109, p. 87, 2016. 
pretendia despejar os moradores sem providenciar abrigos alternativos ${ }^{59}$. Após a decisão, o governo municipal apelou para a Suprema Corte de Apelação (SCA), que reverteu a decisão do Tribunal Regional e concluiu que os despejos eram autorizados pela Constituição. Em prol dos residentes, a SCA apenas determinou que a cidade tinha o dever de providenciar abrigo para aqueles que perdessem a sua moradia60;

Recorrendo da decisão proferida pela SCA, os residentes conseguiram levar a ação à Corte Constitucional, que aceitou o caso em maio de 2007. No dia 30 de agosto, a Corte expediu a primeira ordem para que um Compromisso Significativo fosse realizado entre as partes envolvidas no litígio. A decisão, redigida pelo juiz Zakeria Yacoob, determinou que:

A cidade de Joanesburgo e os demandantes devem estabelecer entre si um compromisso significativo assim que possível, em um esforço para resolver as diferenças e dificuldades expostas nesta ação à luz dos valores da Constituição, dos deveres constitucionais e estatutários do município e dos direitos e deveres dos cidadãos em questão ${ }^{61}$.

Após dialogarem por alguns meses, as partes chegaram a um acordo parcial. Dentre outras determinações, o governo municipal concordou em não realizar o despejo e implementar medidas que melhorassem os prédios e a vida dos seus moradores, como limpeza da área residencial, acesso à água e saneamento básico ${ }^{62}$. A cidade também concordou em reformar vários outros prédios localizados na periferia da cidade, fornecendo serviços públicos essenciais para os moradores da região, além de limitar quaisquer taxas de aluguel para não mais de $25 \%$ da renda mensal dos ocupantes. Por fim, o governo aceitou continuar o diálogo em longo prazo, buscando soluções para os problemas de moradia.

Encerrada a primeira fase de negociações, as partes retornaram à Corte, buscando não só a aprovação dos termos acordados, como também uma decisão sobre a adequação do acordo aos requisitos apresentados no caso Grootboom. Para a surpresa

59 AFRICA DO SUL. Corte Constitucional da África do Sul. Occupiers of 51 Olivia Road, Berea Township, and 197 Main Street vs city of johannesburg. Braamfontein, 2008. p. 3. Disponível em: http://www.saflii.org/za/ cases/ZACC/2008/1.pdf. Acesso em: 09 mar. 2020.

60 AFRICA DO SUL. Corte Constitucional da África do Sul. Occupiers of 51 Olivia Road, Berea Township, and 197 Main Street vs city of johannesburg. Braamfontein, 2008. p. 2. Disponível em: http://www.saflii.org/za/ cases/ZACC/2008/1.pdf. Acesso em: 09 mar. 2020.

61 The City of Johannesburg and the applicants are required to engage with each other meaningfully and as soon as it is possible for them to do so, in an effort to resolve the differences and difficulties aired in this application in the light of the values of the Constitution, the constitutional and statutory duties of the municipality and the rights and duties of the citizens concerned. AFRICA DO SUL. Corte Constitucional da África do Sul. Occupiers of 51 Olivia Road, Berea Township, and 197 Main Street vs city of johannesburg. Braamfontein, 2008. p. 5. Disponível em: http://www.saflii.org/za/cases/ZACC/2008/1.pdf. Acesso em: 09 mar. 2020.

62 LIEBENBERG, Sandra. Engaging the paradoxes of the universal and particular in human rights adjudication: The possibilities and pitfalls of 'meaningful engagement'. African Human Rights Law Journal, 12, 1-29, p. 15, 2012. 
dos dois lados, em sua decisão final, a Corte não analisou essa questão. Em vez disso, priorizou a formalização do Compromisso Significativo como um requisito constitucional a ser realizado em todos os futuros casos em que o despejo de residentes fosse uma possibilidade ${ }^{63}$. A Corte, na ocasião, elencou quatro características que deveriam acompanhar o remédio estrutural.

Primeiro, o Compromisso deve seguir um padrão de razoabilidade, sendo flexível e adaptável aos contextos específicos de cada caso ${ }^{64}$. Como a própria Corte expressou, “Em alguns casos a medida mais razoável pode ser a construção de moradias permanentes para os desalojados, em outros casos, o razoável pode ser não providenciar moradia alguma. As possibilidades entre esses dois extremos são quase infinitas."65.

Segundo, sempre que uma política pública de larga escala, como um plano de regeneração urbana, puder afetar negativamente algum segmento populacional, a municipalidade deve realizar o Compromisso logo no início do planejamento, ou seja, o diálogo com os cidadãos afetados não deve iniciar apenas na instância judicial, mas na própria etapa de planejamento da política pública. A Corte reconheceu que essa exigência impõe o desenvolvimento de instâncias estatais capazes de lidar com esses diálogos, o que acarretará um custo ao Poder Público. Ainda assim, o governo tem a obrigação de investir recursos na realização do Compromisso antes que a fase litigiosa seja sequer possível. Dessa forma, os grupos afetados se tornam mais do que passivos recipientes de direitos, para serem participantes ativos que ajudam a moldar as políticas públicas e as decisões que têm um impacto direto em suas vidas ${ }^{66}$,

Terceiro, a Corte reconheceu a vulnerabilidade dos cidadãos afetados pelos despejos e a necessidade de representação especializada. Para lidar com essa desigualdade de poderes entre a população e o Poder Público, determinou que grupos da sociedade civil, atuantes na defesa dos direitos fundamentais afetados, têm um importante papel constitucional a desempenhar. Assim, "as organizações da sociedade civil que apoiam as demandas dos grupos afetados deveriam preferencialmente facilitar o processo de

63 FUO, Oliver Njuh. Public participation in decentralised governments in Africa: Making ambitious constitutional guarantees more responsive. African Human Rights Law Journal, 15, 2015, 167-191.

64 LIEBENBERG, Sandra. Engaging the paradoxes of the universal and particular in human rights adjudication: The possibilities and pitfalls of 'meaningful engagement'. African Human Rights Law Journal, 12, 1-29, p. 16, 2012.

65 It may in some circumstances be reasonable to make permanent housing available and, in others, to provide no housing at all. The possibilities between these extremes are almost endless. AFRICA DO SUL. Corte Constitucional da África do Sul. Occupiers of 51 Olivia Road, Berea Township, and 197 Main Street vs city of johannesburg. Braamfontein, 2008. p. 12. Disponível

66 MAHOMEDY, Sameera. The potential of meaningful engagement in realsing socioeconomic rights: Addressing quality concerns. 2019. 171 f. Dissertação (Mestrado) - Law, Stellenbosch University, Stellenbosch, 2019. p. 23. 
negociação de todas as formas possíveis" ${ }^{\prime 67}$. Os conhecimentos técnicos que esses grupos possuem são fundamentais para que as negociações sejam bem-sucedidas ${ }^{68}$.

Por fim, a Corte determinou que o governo deve desenvolver e manter um arquivo público sobre cada Compromisso, para que o Judiciário possa, posteriormente, analisar não só o resultado das negociações, mas o próprio procedimento utilizado para promover o diálogo entre as partes. Enfatizou que o sigilo seria contraproducente para assegurar a eficiência do processo, ressaltando que esses registros permitiriam ao Judiciário avaliar se a municipalidade adotou todas as medidas necessárias para alcançar um acordo com os grupos afetados. No entendimento da Corte, a falha em realizar o Compromisso, independentemente de considerações substanciais quanto a política pública a ser desenvolvida pelo governo municipal, pode, por si só, ser razão suficiente para negar um pedido de despejo ${ }^{69}$.

\subsection{O caso Joe Slovo e o aprimoramento do remédio estrutural}

O outro caso paradigmático que contribuiu para o aprimoramento do Compromisso Significativo foi o caso Joe Slovo, cujos aspectos relevantes serão aqui explicados.

Em 2008, a cidade de Cape Town iniciou a implementação do N2 Gateway, projeto de desenvolvimento urbano destinado a construir casas de baixo custo aos moradores, mas que oferecessem adequadas condições de vida ${ }^{70}$. O projeto fazia parte da política Breaking New Ground (BNG) ${ }^{71}$, adotada pela África do Sul, desde 2004, como tentativa de aprimorar as residências das periferias do país, em resposta ao caso Grootboom $^{72}$. A comunidade de Joe Slovo, com mais de 20.000 residentes, seria diretamente afetada pelo N2 Gateway.

67 Civil society organizations that support the peoples' claims should preferably facilitate the engagement process in every possible way. AFRICA DO SUL. Corte Constitucional da África do Sul. Occupiers of $\mathbf{5 1}$ Olivia Road, Berea Township, and 197 Main Street vs city of johannesburg. Braamfontein, 2008. p. 14. Disponível 68 Proceduralisation's Triumph and Engagement's Promise in Socio-Economic Rights Litigation. South African Journal On Human Rights, [s.I.], v. 27, n. 1, p. 107-126, p. 122, jan. 2011

69 AFRICA DO SUL. Corte Constitucional da África do Sul. Occupiers of 51 Olivia Road, Berea Township, and 197 Main Street vs city of johannesburg. Braamfontein, 2008. p. 14. Disponível em: http://www.saflii.org/za/ cases/ZACC/2006/11.html.pdf. Acesso em: 11 mar. 2020.

70 MCLEAN, Kirsty. Meaningful Engagement: One Step Forward or Two Back? Some thoughts on Joe Slovo. Constitutional Court Review, Johannesburg, v. 3, p. 223-242, p. 224, 2010.

71 O BNG é um plano nacional do governo sul-africano, criado em 2004, com o intuito de erradicar as moradias informais no país, no menor tempo possível. Com base nele, foram desenvolvidas várias políticas de reestruturação urbana, para reformar assentamentos informais, como no caso de Joe Slovo. ÁFRICA DO SUL. Breaking New Groung. Pretória, 2004. Disponível em: http://housingfinanceafrica.org/app/uploads/South-Africa-Breaking New-Ground-BNG.pdf. Acesso em: 10 mar. 2020.

72 RAY, Brian. Engaging with Social Rights: Procedure, Participation, and Democracy in South Africa's Second Wave. Cambridge: Cambridge University Press, 2016. p. 119. 
Joe Slovo era um dos maiores assentamentos informais da cidade de Cape Town, um verdadeiro símbolo de marginalização, exclusão econômica e desigualdade social $^{73}$. A sua ocupação teve início nos anos 1990, e, como explica Kotzé74, as casas da comunidade eram precárias, construídas com materiais inflamáveis e carentes de serviços públicos básicos, como acesso à água e ao saneamento básico. Geralmente, reformas como as propostas pelo projeto N2 Gateway não demandavam a remoção dos moradores, sendo realizadas com a sua presença no local. Nesse caso, contudo, o governo optou por uma reforma mais ampla, o que exigiria a realocação dos moradores de Joe Slovo, para a região de Delft.

Antes de iniciar as realocações, o governo municipal fez algumas reuniões com os moradores da comunidade. A finalidade não era dialogar para construir uma solução para o problema, visto que ela já estava pronta, mas esclarecê-los sobre o que havia sido decidido e como o plano seria implementado. Muitos residentes concordaram com o plano, tendo em vista que a cidade e a empresa responsável pela regeneração urbana, Tubelhisha Homes, asseguraram que a maior parte dos moradores poderiam retornar para Joe Slovo, pagando aluguéis bem mais baixos ${ }^{75}$. Mas quando a primeira das três fases do projeto foi concluída, nenhuma das novas casas foi destinada aos moradores.

Decepcionados com as promessas que não foram cumpridas, os residentes organizaram protestos formais e informais, com o objetivo de impedir o prosseguimento do N2 Gateway. Tentando contornar a situação, a cidade de Cape Town recorreu ao Tribunal Regional, para assegurar o despejo dos residentes. O Tribunal ordenou que as realocações deveriam continuar, afirmando também que o governo municipal já havia dedicado esforço suficiente para dialogar com os moradores ${ }^{76}$.

Com base nessa decisão, os residentes apelaram diretamente para a Corte Constitucional, que produziu duas decisões sobre o caso. A primeira, feita em 2009 e chamada de Joe Slovo I, levou em consideração que, diferentemente de Olivia Road, em Joe Slovo, a realocação dos moradores fazia parte de uma política pública especificamente destinada a assegurar o direito à moradia dos próprios residentes, garantindo-lhes também uma moradia temporária ${ }^{77}$. Dessa forma, a Corte autorizou a realocação dos

\footnotetext{
73 CHENWI, Lilian. Democratizing the socio-economic rights-enforcement process. In: GARCÍA, Helena Alviar; KLARE, Karl; WILLIAMS, Lucy A. (Ed.). Social and Economic Rights in Theory and Practice: Critical Inquiries. Nova York: Routledge Research In Human Rights Law, 2014. p. 178-196, p. 188.

74 KOTZÉ, Tina. Effective relief regarding residential property following a failure to execute an eviction order. 2016. 229 f. Tese (Doutorado) - Curso de Direito, Stellenbosch University, Stellenbosch, 2016. p. 77-78

75 PILLAY, A. Toward effective social and economic rights adjudication: The role of meaningful engagement. International Journal Of Constitutional Law, [s.I.], v. 10, n. 3, p. 732-755, p. 742, jul. 2012.

76 KOTZÉ, Tina. Effective relief regarding residential property following a failure to execute an eviction order. 2016. 229 f. Tese (Doutorado) - Curso de Direito, Stellenbosch University, Stellenbosch, 2016. p. 79.

77 RADEBE, Sibusiso Blessing. The protection of the right of access to adequate housing by the south african Constitutional Court. 2013. 190 f. Dissertação (Mestrado) - Curso de Direito, Stellenbosch University, Stellenbosch, 2013. p. 130.
} 
moradores, no entanto, antes que o N2 Gateway pudesse prosseguir, seria necessário realizar um Compromisso Significativo entre a comunidade e a cidade, para decidir a melhor forma de implementar o projeto.

Ao utilizar o Compromisso Significativo, a Corte fixou parâmetros e objetivos que deveriam guiar as negociações das partes envolvidas. A lista de metas a serem alcançadas incluía:

Primeiro, a ordem desta Corte impõe uma obrigação aos demandados de garantir que $70 \%$ dos novos lares construídos no local do assentamento informal Joe Slovo são alocados a essas pessoas que atualmente residem lá ou que foram residentes, mas se mudaram após o lançamento do N2 Gateway Housing Project. Em segundo lugar, a ordem desta Corte especifica a qualidade do alojamento temporário em que os ocupantes serão alojados após o despejo; e terceiro, a ordem deste tribunal exige um processo contínuo do envolvimento entre os residentes e os demandados em relação ao processo de realocação ${ }^{78}$.

Em segundo lugar, a Corte decidiu reter a sua jurisdição sobre o caso, exigindo que as partes reportassem o andamento e os resultados do diálogo, permitindo que, caso houvesse alguma ilegalidade no processo, as partes pudessem retornar à Corte, requisitando a sua interferência. Ray ${ }^{79}$ explica que as duas medidas foram adotadas para pressionar a cidade de Cape Town a manter um diálogo efetivo com a comunidade afetada e para que o governo municipal reconsiderasse a decisão de realocá-los para Delft.

Iniciado o diálogo com os moradores, a cidade de Cape Town decidiu rever o seu posicionamento. Tendo em vista os parâmetros estabelecidos pela Corte, concluiu que seria viável seguir com o N2 Gateway sem precisar remover os residentes de suas moradias, fazendo todos os aprimoramentos necessários com os moradores em suas residências ${ }^{80}$. Importante ressaltar que esse era o desejo dos moradores desde o início do

\footnotetext{
78 First, this Court's order imposes an obligation upon the respondents to ensure that $70 \%$ of the new homes to be built on the site of the Joe Slovo informal settlement are allocated to those people who are currently residente there or who were resident there but moved away after the N2 Gateway Housing Project had been launched. Secondly, this Court's order specifies the quality of the temporary accommodation in which the occupiers will be housed after the eviction; and thirdly, this Court's order requires an ongoing process of engagement between the residents and the respondents concerning the relocation process. Corte Constitucional. Residents of Joe Slovo Community, Western Cape v Thebelisha Homes and Others (CCT 22/08). Braamfontein, 2009. p. 3. Disponível em: http://www.saflii.org/za/cases/ZAGPHC/2008/255.pdf. Acesso em: 23 mar. 2020.

79 RAY, Brian. Engaging with Social Rights: Procedure, Participation, and Democracy in South Africa's Second Wave. Cambridge: Cambridge University Press, 2016. p. 121.

80 CHENWI, Lilian. Democratizing the socio-economic rights-enforcement process. In: GARCÍA, Helena Alviar; KLARE, Karl; WILLIAMS, Lucy A. (Ed.). Social and Economic Rights in Theory and Practice: Critical Inquiries. Nova York: Routledge Research In Human Rights Law, 2014. p. 178-196, p. 190.
} 
litígio. Analisando o desfecho do caso, Pillay ${ }^{81}$ defende que a interpretação substancial do direito à moradia, com detalhadas especificações que deveriam ser seguidas pelo governo municipal, e a retenção da jurisdição para supervisionar as negociações, proporcionaram o resultado positivo obtido. Utilizando essas medidas, a Corte conseguiu não só promover o diálogo entre as partes, mas, indiretamente, pressionar o governo municipal a rever a sua decisão inicial.

Assim, já que não havia mais necessidade de realocação dos moradores e que as outras reformas prometidas pelo Poder Público seriam realizadas com eles em suas residências, a Corte, em 2011, decidiu revogar a autorização para o despejo dos residentes. Esse caso ficou conhecido como Joe Slovo $/ /^{82}$ e encerrou a ameaça de despejo dos moradores.

\subsection{A importância da participação pública nos processos estruturais e as contribuições do Compromisso Significativo}

Com base nos casos analisados, é possível observar que o Compromisso Significativo, além de dar voz aos segmentos sociais marginalizados, contribui para soluções eficientes dos litígios enfrentados, proporcionando também um diálogo entre o Judiciário, a comunidade afetada e o Executivo.

Em termos conceituais, é possível defini-lo como um processo determinado pelo Judiciário, no qual se estabelece um diálogo entre cidadãos e comunidades, de um lado, e o Poder Público, de outro, de tal forma que essas partes tentam, a partir da compreensão das perspectivas do outro, formular um acordo sobre a implementação de programas socioeconômicos que afetam essa população.

Segundo Gloppen ${ }^{83}$, o sucesso dos litígios estruturais depende de quatro fatores: a possibilidade de os grupos afetados terem voz e acesso ao Judiciário; a capacidade de resposta dos tribunais demandados, aceitando os litígios; a habilidade dos juízes para encontrar meios legais adequados para assegurar os direitos econômicos e sociais; e o comprometimento das autoridades políticas com o cumprimento das decisões proferidas. Para a autora, é fundamental que haja uma maior participação da população afetada na superação da omissão política. Em um modelo de democracia deliberativa,

81 PILLAY, A. Toward effective social and economic rights adjudication: The role of meaningful engagement. International Journal Of Constitutional Law, [s.l.], v. 10, n. 3, p. 732-755, p. 750, jul. 2012.

82 ÁFRICA DO SUL. Corte Constitucional. Residents of Joe Slovo Community, Western Cape v Thebelisha Homes and Others (CCT 22/08). Braamfontein, 2011. Disponível em: http://www.saflii.org/za/cases/ ZACC/2011/8.pdf. Acesso em: 23 mar. 2020.

83 GLOPPEN, Siri. Social Rights Litigation as Transformation: South African Perspectives. Chr. Michelsen Institute, CMI Working Paper WP 2005: 3, p. 3-4. 
as Cortes podem se tornar um ambiente institucionalizado para ouvir as vozes marginalizadas e chamar a atenção para os seus clamores ${ }^{84}$.

Há vários argumentos em prol de um processo estrutural dialógico, baseados tanto em valores intrínsecos, quanto extrínsecos. Tratando do tema, Liebenberg ${ }^{85}$ afirma que a participação dos grupos sociais afetados na formulação de políticas públicas tem um valor intrínseco, pois permite que grupos historicamente marginalizados e economicamente excluídos possam ter expressão política e, efetivamente, influenciar o processo de tomada de decisões públicas. Para aprofundar a democracia participativa, é preciso que os cidadãos possam atuar nas instituições públicas de seu país, influenciando a formulação das políticas que afetam diretamente a sua comunidade, e isso inclui a instância judicial ${ }^{86}$.

A jurisprudência sobre o Compromisso Significativo deixa clara a estreita ligação entre os direitos socioeconômicos e a democracia participativa. A Constituição sul-africana de 1996 busca promover um modelo de democracia participativa, incentivando o engajamento dos cidadãos nos processos de decisão pública que possam afetar as suas vidas ${ }^{87}$. O direito de ser ouvido no processo de decisão pública é particularmente importante para os membros de grupos que são vítimas de marginalização social, econômica e política ${ }^{88}$. Assim, ainda que a Constituição não preveja expressamente o Meaningful Engagement, a Corte Constitucional pôde inferi-lo de vários dispositivos constitucionais. Nesse sentido, a Corte explicou, no julgamento do caso Doctors for Life International, a importância do direito à participação:

Hoje, é constitutivo de suas identidades como cidadãos que eles tenham não só a chance de falar, mas também tenham a garantia de que serão ouvidos. Isso seria de especial relevância para aqueles que, no momento, podem se sentir politicamente desfavorecidos porque carecem de ensino superior, acesso a recursos e fortes conexões políticas. $O$ envolvimento do público fortalece, em vez de prejudicar, a democracia formal, respondendo e negando alguns de seus déficits funcionais ${ }^{89}$.

84 LIEBENBERG, Sandra. Engaging the paradoxes of the universal and particular in human rights adjudication: The possibilities and pitfalls of 'meaningful engagement'. African Human Rights Law Journal, 12, 1-29, p. 11, 2012.

85 LIEBENBERG, Sanda. Participatory Justice in Social Rights Adjudication. Human Rights Law Review, [s.l.], v. 18, n. 4, p.623-649, p. 626, 21 nov. 2018.

86 HELLER, Patrick. Democratic deepening in india and south africa. Journal of Asian and African Studies, v. 44, n. 1, p. 123-149, p. 130-131, 2009.

87 AUGUS, Vanessa Mary. The mechanism of meaningful engagement in socio-economic rights cases as an enabler for the realisation of transformation and capacity building of the poor. 2018. $84 \mathrm{f}$. Dissertação (Mestrado) - Curso de Direito, Universidade de Pretoria, Pretoria, 2018. p. 19-20.

88 LIEBENBERG, Sandra. Participatory Justice in Social Rights Adjudication. Human Rights Law Review, [s.l.], v. 18, n. 4, p.623-649, p. 624-625, 21 nov. 2018.

89 It is constitutive of their dignity as citizens today that they not only have a chance to speak, but also enjoy the assurance they will be listened to. This would be of special relevance for those who may feel politically 
No que diz respeito à participação comunitária, é importante ressaltar que o Compromisso Significativo não é uma mera consulta às populações atingidas pela ação ou omissão estatal ${ }^{90}$. A consulta pública não assegura que as manifestações dos cidadãos sejam incorporadas às decisões do Executivo. O Compromisso ocorre quando a Administração Pública e a comunidade escutam-se mutuamente, com o intuito de alcançar pontos em comum. As comunidades envolvidas devem ser consideradas como partes integrantes do processo de construção das políticas públicas que serão adotadas, estando o Poder Público obrigado a executar o que pactuar com esses grupos.

Mas também há razões instrumentais para se optar por esse diálogo entre Poder Público e cidadãos. Primeiramente, há um importante ganho epistêmico na tomada de decisão pública ${ }^{91}$. Com a participação dos grupos afetados, os gestores públicos podem analisar melhor o problema enfrentado, confrontando suas ideias com as opiniões e as necessidades daquelas pessoas diretamente afetadas pela atuação estatal, sendo possível alcançar uma solução mais adequada ao problema. O ganho epistêmico aponta uma solução para o problema da incapacidade técnica do Judiciário.

Em ambientes deliberativos, nos quais há uma pluralidade de ideias, cada indivíduo pode comunicar ao outro experiências e discernimentos que complementam os que o outro já possui, fazendo com que o grupo, como um todo, tenha um importante ganho epistêmico para fundamentar as decisões que serão tomadas ${ }^{92}$. Isso é ainda mais relevante em processos estruturais, já que em intervenções unilaterais, nas quais os grupos afetados não são ouvidos, é comum que as verdadeiras causas do problema não sejam enfrentadas, adotando-se medidas paliativas e temporárias.

No diálogo a ser construído entre as partes, o Judiciário desempenha um importante papel para promover o ganho epistêmico. O Poder Público poderia tentar impor uma decisão previamente elaborada, sem apresentar razões técnicas que justifiquem as medidas que pretende adotar. As suas decisões podem estar baseadas em preferências indevidas, muito mais do que em fundamentos empíricos. Por isso, Judiciário pode

disadvantaged at present because they lack higher education, access to resources and strong political connections. Public involvement accordingly strengthens rather than undermines formal democracy, by responding to and negating some of its functional deficits. ÁFRICA DO SUL. Corte Constitucional da África do Sul. Doctors for Life International v Speaker of the National Assembly and Others (CCT 12/05). Braamfontein, 2006. p. 123 124. Disponível em: http://www.saflii.org/za/cases/ZACC/2006/11.html.pdf. Acesso em: 11 mar. 2020.

90 CHENWI, Lilian; TISSINGTON, Kate. Engaging meaningfully with government on socioeconomic rights: a focus on the right to housing. University of the Western Cape: Community Law Centre, March, 2010. p. 10.

91 MAKABA, Ipeleng Josephinah. Citizen participation and meaningful engagement as effective tools for good governance in policy-making and realisation of economic, social and cultural rights. 2018.67 f. Dissertação (Mestrado) - Curso de Direito, University Of Pretoria, Pretoria, 2018. p. 10.

92 WALDRON, Jeremy. A dignidade da legislação. Tradução: Luís Carlos Borges. São Paulos: Martins Fontes, 2003. p. 143. 
analisar se o órgão administrativo adotou uma fonte qualificada de informações, capaz de embasar a solução do problema em questão. Como bem alertam Scott e Sturm,“Não é suficiente apresentar razões. As justificativas devem estar fundamentadas em registros de informação." ${ }^{\prime 93}$.

Apesar desse papel de supervisão, no Compromisso Significativo, não é a instância judicial que formula as políticas públicas, mas sim o Executivo, que deve trabaIhar em conjunto com os segmentos populacionais afetados. Assim, o governo retém o poder de tomar as decisões administrativas e políticas que são consistentes com os direitos socioeconômicos ${ }^{94}$. E isso é uma das principais contribuições que ele pode dar para os processos estruturais no Brasil. O seu caráter dialógico proporciona duas vantagens simultâneas: enquanto aumenta a legitimidade da decisão por meio da participação popular, enfraquece os argumentos de ameaça à separação de poderes e incapacidade técnica do Judiciário para formular políticas públicas, geralmente utilizados contra os processos estruturais.

Segundo, há maior transparência na formulação de políticas públicas ${ }^{95}$, na medida em que o governo precisa justificar, publicamente, as escolhas que pretende realizar ao implementar uma política pública, ouvindo as necessidades dos grupos afetados $^{96}$. Isso é importante tanto para que os cidadãos fiscalizem a ação estatal, como também para permitir uma intervenção judicial fundamentada, tendo em vista que o Judiciário saberá como ocorreu o processo de tomada de decisão e o que motivou as partes durante as negociações. A transparência é um dos elementos mais importantes do experimentalismo, permitindo que o status quo seja exposto e, por meio das pressões sociais, modificado ${ }^{97}$.

A transparência e o controle público são fundamentais para que os direitos socioeconômicos desempenham a sua função de destabilization rights. Na definição de Unger $^{98}$, os direitos de desestabilização podem ser compreendidos como chaves de

93 It is not enough to give reasons. These reasons must be supported by the informational record. SCOTT, Joanne; STURM, Susan. Courts as catalysts: re-thinking the judicial role in new governance. Columbia Journal of European Law, v. 13, p. 565-594, p. 587, 2006.

94 LIEBENBERG, Sandra. Participatory Justice in Social Rights Adjudication. Human Rights Law Review, [s.I.], v. 18, n. 4, p.623-649, p. 641, 21 nov. 2018.

$95 \mathrm{CHENWI}$, Lilian. A new approach to remedies in socioeconomic rights adjudication: Occupiers of 51 Olivia Road and Others v City of Johannesburg and Others. Constitutional Court Review, Volume 2, Issue 1, p. 371 393, p. 388, Jan 2009

96 DAVIS, Dennis M. The scope of the judicial role in the enforcement of social and economic rights: limits and possibilities viewed from the South African experience. In: GARCÍA, Helena Alviar; KLARE, Karl; WILLIAMS, Lucy A. (Ed.). Social and Economic Rights in Theory and Practice: Critical Inquiries. Nova York: Routledge Research In Human Rights Law, 2014. p. 197-214, p. 208.

97 SABEL, Charles F.; SIMON, William H. Destabilization rights: how public law litigation succeeds. Cambridge: Harvard Law Review, 2004. p. 1073.

98 UNGER, Roberto Mangabeira. False necessity: anti-necessitarian social theory in the service of radical democracy. Cambridge: Cambridge University Press, 1987. p. 530-531. 
acesso às instituições públicas que, cronicamente, falham em cumprir suas obrigações constitucionais e que estão relativamente isoladas do controle político popular. Complementando essa definição, o autor afirma:

Direitos de desestabilização protegem o interesse do cidadão em abrir as organizações de grande escala ou as amplas áreas de prática social que permanecem fechadas aos efeitos desestabilizadores de conflitos comuns e, desse modo, sustentam hierarquias isoladas de poder e privilégios. A combinação de direitos de imunidade com direitos de desestabilização dá expressão jurídica ao mecanismo institucional central de todo o plano constitucional. $O$ direito à desestabilização vincula o interesse coletivo em garantir que todas as instituições e práticas possam ser criticadas e revisadas, em prol do interesse individual de evitar a opressão99.

Em terceiro lugar, aumenta-se a legitimidade das decisões tomadas, gerando uma maior cooperação pública e um maior comprometimento com a sua implementação, seja por parte do Estado, seja por parte dos cidadãos ${ }^{100}$. As sentenças estruturais dialógicas oferecem uma alternativa para o dilema da justiciabilidade dos direitos sociais. Tratando do dilema, Michelman ${ }^{101}$ explica que, com a constitucionalização dos direitos socioeconômicos, o Judiciário deve escolher entre uma postura ativista ou de autoconstrição, decisão que sempre leva ou ao embaraço ou ao descrédito institucional. Por um lado, a instância judicial intervém diretamente na formulação de políticas públicas, ainda que não tenha a capacidade técnica necessária para reorganizar as prioridades do orçamento público e que contrarie a vontade política majoritária. Por outro, adotando uma postura deferente, o Judiciário pode esvaziar todo o conteúdo normativo dos direitos socioeconômicos, deixando-os dependentes da discricionariedade do Poder Público.

O Compromisso Significativo, todavia, mostra que o Judiciário não precisa ficar refém dessas duas opções. É possível promover a efetividade dos direitos sociais, respeitando as competências próprias da Administração Pública e dando voz aos segmentos

\footnotetext{
99 Destabilization rights protect the citizen's interest in breaking open the large-scale organizations or the extended areas of social practice that remain closed to the destabilizing effects of ordinary conflict and thereby sustain insulated hierarchies of power and advantage. The combination of immunity rights with destabilization rights gives legal expression to the central institutional mechanism of the whole constitutional plan. The destabilization entitlement ties the collective interest in ensuring that all institutions and practices can be criticized and revised to the individual interest in avoiding oppression. UNGER, Roberto Mangabeira. False necessity: anti-necessitarian social theory in the service of radical democracy. Cambridge: Cambridge University Press, 1987. p. 530.

100 TYLER, Tom R. Procedural Justice, Legitimacy, and the Effective Rule of Law. Crime And Justice, [s.l.], v. 30, p. 283-357, p. 350, jan. 2003.

101 MICHELMAN, F. I. The constitution, social rights, and liberal political justification. International Journal Of
} Constitutional Law, [s.I.], v. 1, n. 1, p. 13-34, p. 16, jan. 2003. 
populacionais afetados. Como argumenta Muller ${ }^{102}$, a parceria entre o grupo afetado e o Estado facilita a formação de uma base comum e compreensão mútuas, facilitando a compreensão e o engajamento dos setores políticos na solução das omissões políticas. Sem o engajamento destes setores, as sentenças estruturais tendem ao fracasso e, quanto maior a ingerência do Judiciário no âmbito de atuação dos demais órgãos estatais, maiores as chances de ineficiência da decisão.

Quando o Judiciário intervém de forma dialógica, os setores políticos poderão ganhar mais crédito pela solução implementada ${ }^{103}$, visto que possuem uma maior margem de discricionariedade para sua atuação. Consequentemente, há um maior comprometimento dos órgãos administrativos com a implementação de uma solução efetiva para o problema enfrentado. Além de atenuar as críticas da separação de poderes e da incapacidade técnica, o comprometimento dos órgãos administrativos é fundamental para evitar a ocorrência do efeito backlash, que também é apontado como um dos principais riscos dos processos estruturais.

Sintetizando os argumentos expostos neste tópico, constata-se que as sentenças estruturais participativas, como o Compromisso Significativo, têm um importante papel na concretização dos direitos fundamentais. Isso porque respondem satisfatoriamente à crítica da separação de poderes, respeitam a capacidade técnica do Executivo para formular políticas públicas, e promovem o engajamento das partes com a solução do litígio, seja o Poder Público, sejam os segmentos populacionais afetados ${ }^{104}$.

\section{CONCLUSÃO}

A concretização judicial dos direitos econômicos, sociais e culturais é marcado por um paradoxo identificado por Robert Alexy: se os DESCs não puderem ser implementados por órgãos judiciais, eles correm o risco de serem transformados em mera retórica política. Por outro lado, se esses direitos forem exigíveis na via judicial, há o risco de deslocamento das decisões políticas, de índole social, do Legislativo e do Executivo para o Poder Judiciário ${ }^{105}$.

Esse paradoxo, contudo, pode ser minimizado se for reconhecido que não há uma dicotomia absoluta entre o amplo e irrestrito ativismo judicial e a total deferência à atuação política. É possível promover a efetividade dos direitos sociais prestacionais,

102 MULLER, Gustav. Conceptualizing "Meaningful Engagement" as a Deliberative Democratic Partnership. Stellenbosch Law Review, Stellenbosch, v. 22, p.742-758, p. 756-757, 2011.

103 SARLET, Ingo Wolfgang. Direito fundamentais sociais e mínimo existencial - notas sobre um possível papel das assim chamadas decisões estruturais na perspectiva da jurisdição constitucional. In: ARENHART, Sérgio Cruz; JOBIM, Marco Félix (Org.). Processos Estruturais. Salvador: Juspodivm, 2017. p. 203-232, p. 230.

104 LIEBENBERG, Sandra. Remedial principles and meaningful engagement in education rights disputes. Potchefstroomse Elektroniese Regsblad, v. 19, n. 1, p. 1-43, p. 38, 2016.

105 ALEXY, Robert. Teoria de los derechos fundamentales. Madrid: Centro de Estudios Constitucionales, 1997. 
respeitando as competências próprias dos poderes políticos, sobretudo se for desenvolvido um modelo de processo estrutural mais aberto à participação comunitária e ao diálogo interinstitucional.

O Compromisso Significativo, modelo desenvolvido pela Corte Constitucional sul-africana, pode ser um ponto de partida para construir um modelo que caminha nessa direção. Nesse modelo, busca-se a participação dos segmentos populacionais afetados pelas omissões políticas, com vantagens intrínsecas e extrínsecas.

Por um lado, as comunidades afetadas são tratadas com dignidade, podendo influenciar a formulação das políticas públicas que lhes dizem respeito. Assim, os grupos sociais afetados não são vistos apenas como objetos da ação estatal, mas como parceiros na construção das soluções para os problemas enfrentados.

Por outro lado, existem razões instrumentais para promover a participação pública. Como visto, há um ganho epistêmico no processo de tomada de decisão, já que mais pontos de vista serão levados em consideração e, consequentemente, há uma maior chance de identificar as reais causas do problema. Além disso, há maior transparência na atuação estatal, que precisa justificar publicamente suas decisões, e, por fim, aumenta-se a chance de comprometimento do Poder Público com a resolução da demanda. Afinal, as medidas a serem executadas não serão impostas pelo Judiciário, mas construídas, por meio do diálogo, com os segmentos populacionais afetados.

Nesse sentido, o Compromisso Significativo é capaz de minimizar as três críticas centrais que costumam ser feitas aos processos estruturais. A utilização de um remédio estrutural dialógico evita a violação à separação de poderes, mitiga a preocupação quanto a incapacidade técnica do Judiciário para formular políticas públicas e diminui as chances de ocorrer um efeito backlash. Mesmo que se reconheçam diferenças na realidade jurídica e social brasileira, quando comparada à realidade sul-africana, pode-se dizer que o exemplo sul-africano pode contribuir para o aperfeiçoamento dos processos estruturais no Brasil, merecendo maior atenção por parte dos juristas brasileiros que querem repensar o papel do povo no constitucionalismo contemporâneo.

\section{REFERÊNCIAS}

ÁFRICA DO SUL. Breaking New Ground. Pretória, 2004. Disponível em: http://housingfinanceafrica.org/app/uploads/South-Africa-Breaking-New-Ground-BNG.pdf. Acesso em: 01 abr. 2020.

ALEXY, Robert. Teoria de los derechos fundamentales. Madrid: Centro de Estudios Constitucionales, 1997.

ARENHART, Sérgio Cruz. Processo multipolar, participação e representação de interesses concorrentes. In: ARENHART, Sérgio Cruz; JOBIM, Marco Félix (Org.). Processos Estruturais. Salvador: Juspodivm, 2017. p. 423-448. 
ARIZA, Libardo José. The Economic and Social Rights of Prisoners and Constitutional Court Intervention in the Penitentiary System in Colombia. In: MALDONADO, Daniel Bonilla. Constitutionalism of the Global South: The activist tribunals of India, South Africa, and Colombia. New York: Cambridge University Press, 2013. p. 129-162.

AUGUS, Vanessa Mary. The mechanism of meaningful engagement in socio-economic rights cases as an enabler for the realisation of transformation and capacity building of the poor. 2018. 84 f. Dissertação (Mestrado) - Curso de Direito, Universidade de Pretoria, Pretoria, 2018.

BEATTY, David M. A essência do Estado de direito. Tradução: Ana Aguiar Cotrim. São Paulo: WMF Martins Fontes, 2014.

BUENO, C. C. ; FACHIN, Melina Girardi . Decisões estruturantes na jurisdição constitucional brasileira: critérios processuais da tutela jurisdicional de direitos prestacionais. Revista de Estudos Institucionais, v. 4, p. 211-246, 2018.

CAMPOS, Carlos Alexandre de Azevedo. Estado de Coisas Inconstitucional. Salvador: Juspodium, 2016.

CARVALHO, Márcia Haydée Porto de; MURAD, Rakel Dourado. O caso da vaquejada entre o Supremo Tribunal Federal e o Poder Legislativo: a quem cabe a última palavra?. Revista de Biodireito e Direito dos Animais, [s.I.], v. 3, n. 2, p. 18-37, dez. 2017.

CARVALHO, Osvaldo Ferreira de. As políticas públicas como concretização dos direitos sociais. Revista de Investigações Constitucionais, Curitiba, vol. 6, n. 3, p. 773-794, set./dez. 2019.

CHAGAS, Tayná Tavares das et al. Estado de coisas inconstitucional: um estudo sobre os casos colombiano e brasileiro. Revista Quaestio luris, [s.I.], v. 8, n. 4, p. 2.596-2.612, 2015.

CHENWI, Lilian. A new approach to remedies in socioeconomic rights adjudication: Occupiers of 51 Olivia Road and Others v City of Johannesburg and Others. Constitutional Court Review, Volume 2, Issue 1, p. 371 - 393, Jan 2009.

CHENWI, Lilian. Democratizing the socio-economic rights-enforcement process. In: GARCÍA, Helena Alviar; KLARE, Karl; WILLIAMS, Lucy A. (Ed.). Social and Economic Rights in Theory and Practice: Critical Inquiries. Nova York: Routledge Research In Human Rights Law, 2014. p. 178-196.

CHENWI, Lilian; TISSINGTON, Kate. Engaging meaningfully with government on socio-economic rights: a focus on the right to housing. University of the Western Cape: Community Law Centre, March, 2010.

CLOETE, Clireesh Terry. A critical analysis of the approach of the courts in the application of eviction remedies in the pre-constitutional and constitutional context. 2016. $231 \mathrm{f}$. Dissertação (Mestrado) - Curso de Direito, Stellenbosch University, Stellenbosch, 2016. 
DAVIS, Dennis M.. The scope of the judicial role in the enforcement of social and economic rights: limits and possibilities viewed from the South African experience. In: GARCÍA, Helena Alviar; KLARE, Karl; WILLIAMS, Lucy A. (Ed.). Social and Economic Rights in Theory and Practice: Critical Inquiries. Nova York: Routledge Research In Human Rights Law, 2014. p. 197-214, 208.

DIXON, Rosalind. O argumento central a favor da forma fraca de controle de constitucionalidade. Revista Direitos Fundamentais \& Democracia, v. 24, n. 2, p. 5-55, 2019.

FERRAZ, Octavio Luiz Motta. Between activism and deference: social rights adjudication in the Brazilian Supreme Federal Tribunal. In: GARCÍA, Helena Alviar; KLARE, Karl; WILLIAMS, Lucy A. (Ed.). Social and Economic Rights in Theory and Practice: Critical Inquiries. Nova York: Routledge Research In Human Rights Law, 2014. p. 121-137.

FISS, Owen. To make the Constitution a living truth: four lectures on the Structural Injunction. In: ARENHART, Sérgio Cruz; JOBIM, Marco Félix (Org.). Processos Estruturais. Salvador: Juspodivm, 2017. p. 583-607.

FUO, Oliver Njuh. Public participation in decentralised governments in Africa: Making ambitious constitutional guarantees more responsive. African Human Rights Law Journal, 15, 2015, 167-191.

GARAVITO, César Rodríguez; FRANCO, Diana Rodríguez. Cortes y cambio social: Cómo la Corte Constitucional transformó el desplazamiento forzado en Colombia. Bogotá: Colección de Justicia, 2010.

GLOPPEN, Siri. Social Rights Litigation as Transformation: South African Perspectives. Chr. Michelsen Institute, CMI Working Paper WP 2005: 3.

HELLER, Patrick. Democratic deepening in india and south africa. Journal of Asian and African Studies, v. 44, n. 1, p. 123-149, 2009.

JOBIM, Marco Félix. Medidas Estruturantes: da Suprema Corte Estadunidense ao Supremo Tribunal Federal. Porto Alegre: Livraria do Advogado Editora, 2013. p. 91-93.

KOTZÉ, Tina. Effective relief regarding residential property following a failure to execute an eviction order. 2016. 229 f. Tese (Doutorado) - Curso de Direito, Stellenbosch University, Stellenbosch, 2016.

KOZICKI, Katya. Backlash: as "reações contrárias" à decisão do Supremo Tribunal Federal na ADPF no 153. In: SOUZA JÚNIOR, José Geraldo de et al. (Org.). O Direito Achado na Rua: introdução crítica à justiça de transição na América Latina. Brasília: UnB, 2015. v. 7, p. 192-196.

LANDAU, David. The Reality of Social Rights Enforcement. Harvard International Law Journal, v. 53 , n. 1,2012 , p. $190-247$. 
LIEBENBERG, Sandra. Engaging the paradoxes of the universal and particular in human rights adjudication: The possibilities and pitfalls of 'meaningful engagement'. African Human Rights Law Journal, 12, 1-29, 2012.

LIEBENBERG, Sandra. Participatory Justice in Social Rights Adjudication. Human Rights Law Review, [s.I.], v. 18, n. 4, p.623-649, 21 nov. 2018.

LIEBENBERG, Sandra. Remedial principles and meaningful engagement in education rights disputes. Potchefstroomse Elektroniese Regsblad, v. 19, n. 1, p. 1-43, 2016.

LIEBENBERG, Sandra; YOUNG, Katharine G.. Adjudicating social and economic rights: Can democratic experimentalismo help?. In: GARCÍA, Helena Alviar; KLARE, Karl; WILLIAMS, Lucy A. (Ed.). Social and Economic Rights in Theory and Practice: Critical Inquiries. Nova York: Routledge Research In Human Rights Law, 2014. p. 237-257.

MAGALHÃES, Breno Baía. O Estado de Coisas Inconstitucional na ADPF 347 e a sedução do Direito: o impacto da medida cautelar e a resposta dos poderes políticos. Revista Direito GV, [s.l.], v. 15, n. 2, p. 1-37, 2019.

MAHOMEDY, Sameera. The potential of meaningful engagement in realsing socio-economic rights:: Addressing quality concerns. 2019. 171 f. Dissertação (Mestrado) - Law, Stellenbosch University, Stellenbosch, 2019.

MAIA, Isabelly Cysne Augusto. Análise da ADPF no 347 e da inadequabilidade do Estado de Coisas Inconstitucional para a efetivação dos serviços públicos: por novos protagonistas na esfera pública democrática. 2018. 177 f. Dissertação (Mestrado) - Curso de Direito, Universidade Federal do Ceará, Fortaleza, 2018.

MAKABA, Ipeleng Josephinah. Citizen participation and meaningful engagement as effective tools for good governance in policy-making and realisation of economic, social and cultural rights. 2018. 67 f. Dissertação (Mestrado) - Curso de Direito, University Of Pretoria, Pretoria, 2018.

MARMELSTEIN, George. A eficácia incompleta das normas constitucionais: desfazendo um mal-entendido sobre o parâmetro normativo das omissões inconstitucionais. Revista Jurídica da Fa7, Fortaleza, v. 12, n. 1, p.10-28, p. 25, 2015a.

MARMELSTEIN, George. O Estado de Coisas Inconstitucional: uma análise panorâmica. In: OLIVEIRA, Pedro Augusto de; LEAL, Gabriel Prado (Org.). Diálogo Jurídicos Luso-Brasileiros Volume 1 perspectivas atuais de Direto Público: o Direito em tempos de crise. Salvador: Faculdade Baiana de Direito, 2015b, p. 241- 264.

MAAS, Rosana Helena; LEAL, Mônia Clarissa Hennig. Controle judicial de políticas públicas: “controle judicial forte ou fraco"?. Revista Direitos Fundamentais \& Democracia, v. 24, n. 1, p. 191215, 2019. 
MCLEAN, Kirsty. Meaningful Engagement: One Step Forward or Two Back? Some thoughts on Joe Slovo. Constitutional Court Review, Johannesburg, v. 3, p. 223-242, 2010.

MICHELMAN, F. I.. The constitution, social rights, and liberal political justification. International Journal Of Constitutional Law, [s.I.], v. 1, n. 1, p. 13-34, jan. 2003.

MULLER, Gustav. Conceptualizing "Meaningful Engagement" as a Deliberative Democratic Partnership. Stellenbosch Law Review, Stellenbosch, v. 22, p.742-758, 2011.

NEVES, Marcelo. Constitucionalização Simbólica e Desconstitucionalização Fática: Mudança Simbólica de Constituição e Permanência das Estruturas Reais de Poder. Revista de Informação Legislativa, Brasília, v. 33, n.132, p. 321-330, 1996.

OSNA, Gustavo. Nem "tudo", nem "nada" - decisões estruturais e efeitos jurisdicionais complexos. In: ARENHART, Sérgio Cruz; JOBIM, Marco Félix. Processo Estruturais. Salvador: Juspodivm, 2017. p. 177-202.

PEREIRA, Jane Reis Gonçalves; GONÇALVES, Gabriel Accioly . Inconstitucionalidade sistêmica e multidimensional: transformações no diagnóstico das violações à Constituição. JURISPOIESIS, v. 18, p. 130-159, 2015.

PILLAY, A. Toward effective social and economic rights adjudication: The role of meaningful engagement. International Journal Of Constitutional Law, [s.l.], v. 10, n. 3, p. 732-755, p. 750, jul. 2012.

RADEBE, Sibusiso Blessing. The protection of the right of access to adequate housing by the south african Constitutional Court. 2013. 190 f. Dissertação (Mestrado) - Curso de Direito, Stellenbosch University, Stellenbosch, 2013.

RAMOS, Eival da Silva. Ativismo Judicial: parâmetros dogmáticos. 2. ed. São Paulo: Saraiva, 2015.

RAY, Brian. Engaging with Social Rights: Procedure, Participation, and Democracy in South Africa's Second Wave. Cambridge: Cambridge University Press, 2016.

RAY, Brian. Proceduralisation's Triumph and Engagement's Promise in Socio-Economic Rights Litigation. South African Journal On Human Rights, [s.I.], v. 27, n. 1, p. 107-126, jan. 2011.

ROUX, Theunis. Legitimating Transformation: Political Resource Allocation in the South African Constitutional Court. In: GLOPPEN, Siri; GARGARELLA, Roberto; SKAAR, Elin. Democratization and the judiciary: The Accountability Function of Courts in New Democracies. London: Frank Cass Publishers, 2005. p. 66-80.

SABEL, Charles F.; SIMON, William H.. Destabilization rights: how public law litigation succeeds. Cambridge: Harvard Law Review, 2004.

SAMPAIO, Karinne F.. O controle e a implementação do direito à saúde: a jurisprudência da África do Sul. Revista Digital Constituição e Garantia de Direitos, v. 9, p. 85-109, 2016. 
SARLET, Ingo Wolfgang. Direito fundamentais sociais e mínimo existencial - notas sobre um possível papel das assim chamadas decisões estruturais na perspectiva da jurisdição constitucional. In: ARENHART, Sérgio Cruz; JOBIM, Marco Félix (Org.). Processos Estruturais. Salvador: Juspodivm, 2017. p. 203-232.

SCOTT, Joanne; STURM, Susan. Courts as catalysts: re-thinking the judicial role in new governance. Columbia Journal of European Law, v. 13, p. 565-594, 2006.

TYLER, Tom R.. Procedural Justice, Legitimacy, and the Effective Rule of Law. Crime And Justice, [s.I.], v. 30, p. 283-357, jan. 2003.

UNGER, Roberto Mangabeira. False necessity: anti-necessitarian social theory in the service of radical democracy. Cambridge: Cambridge University Press, 1987.

VALLE, Vanice Regina Lírio do. Backlash à decisão do Supremo Tribunal Federal: pela naturalização do dissenso como possibilidade democrática [online]. 2013. p. 9. Disponível em: https:// www.academia.edu/5159210/Backlash_\%C3\%A0_decis\%C3\%A3o_do_Supremo_Tribunal_Federal_pela_naturaliza\%C3\%A7\%C3\%A3o_do_dissenso_como_possibilidade_democr\%C3\%A1 tica. Acesso em: 20 jun. 2020.

VARGAS HERNÁNDEZ, Clara Inés. La garantía de la dimensión objetiva de los derechos fundamentales y labor del juez constitucional colombiano en sede de acción de tutela: El llamado"Estado de cosas inconstitucional" Estudios Constitucionales, v. 1, n. 1, 2003. p. 203-228.

VIEIRA JUNIOR, R. J. A. Separação de Poderes, Estado de Coisas Inconstitucional e Compromisso Significativo: novas balizas à atuação do Supremo Tribunal Federal. Brasília: Núcleo de Estudos e Pesquisas/CONLEG/Senado, Dezembro/2015 (Texto para Discussão no 186). Disponível em: https://www12.senado.leg.br/publicacoes/estudos-legislativos/tipos-de-estudos/textos-para-discussao/td186. Acesso em: 09 mai. 2020.

VIEIRA, J. R.; BEZERRA, R.. Estado de coisas fora do lugar: uma análise comparada entre a Sentencia T025 e a ADPF 347/DF-MC. In: VIEIRA, José Ribas; CAMARGO, Margarida Maria Lacombe; SIDDHARTA, Legale. (Org.). Jurisdição constitucional e direito constitucional internacional. Belo Horizonte: Editora Fórum, 2016. p. 203-223.

VITORELLI, Edilson. Litígios Estruturais: decisão e implementação de mudanças socialmente relevantes pela via processual. In: ARENHART, Sérgio Cruz; JOBIM, Marco Félix (Org.). Processos Estruturais. Salvador: Juspodivm, 2017. p. 369-422.

VITORELLI, Edilson. $\mathbf{O}$ devido processo legal coletivo: representação, participação e efetividade da tutela jurisdicional. 2015. 719 f. Tese (Doutorado) - Curso de Direito, Ciências Jurídicas, Universidade Federal do Paraná, Curitiba, 2015.

WALDRON, Jeremy. A dignidade da legislação. Tradução: Luís Carlos Borges. São Paulos: Martins Fontes, 2003. 
WESSON, Murray. Grootboom and Reassessing: Beyond the Socioeconomic Jurisprudence of the South African Constitutional Court. South African Journal On Human Rights, [s.l.], v. 20, n. 2, p. 284-308, jan. 2004.

WILSON, Stuart. Litigating Housing Rights in Johannesburg's Inner City: 2004 — 2008. South African Journal On Human Rights, [s.l.], v. 27, n. 1, p.127-151, jan. 2011.

WILSON, Stuart; DUGARD, Jackie. Constitutional Jurisprudence. Socio-economic Rights In South Africa, [s.l.], p. 35-62, 2011. Cambridge University Press. 